\title{
La simulación en salud: una estrategia de evaluación y formación por competencias
}

Claudia Espinal Correa Carlos Andrés Álvarez Zuluaga Jorge Humberto Rubio Elorza Mauricio Vasco Ramírez 



\section{La simulación en salud: una estrategia de evaluación y formación por competencias}

Claudia Espinal Correa

Carlos Andrés Álvarez Zuluaga

Jorge Humberto Rubio Elorza

Mauricio Vasco Ramírez 


\section{¿Cómo citar este libro? / How to cite this book?}

Espinal Correa C, Álvarez Zuluaga CA, Rubio Elorza JH, Vasco Ramírez M. La simulación en salud: una estrategia de evaluación y formación por competencias (Working papers $\mathrm{N} .^{\circ} 2$ ). Ediciones Universidad Cooperativa de Colombia, 2021. Doi: https://dx.doi.org/10.16925/wpgp.04 


\section{Resumen}

La simulación clínica no es una novedad. Hace ya mucho se distanció de sus orígenes en la aviación y colonizó áreas como la educación en salud. En este libro se la presenta como una tecnología que, acompañada de recursos como los simuladores y estrechamente ligada al campo de la pedagogía y la didáctica, se pone en un lugar privilegiado dentro de la compleja relación de enseñanza-aprendizaje, es decir, se convierte en una estrategia que contribuye al desarrollo y potenciamiento de las habilidades y destrezas requeridas por las disciplinas en las que se encuentra inmersa, a la vez que favorece la toma de decisiones del futuro profesional, en nuestro caso, del área de la salud. Parte de esto radica en que, una vez insertada en la malla curricular de los programas de educación superior, la simulación permite escalar varios grados de complejidad y situaciones: desde la adquisición de habilidades y destrezas básicas, hasta la compleja toma de decisiones cuya encrucijada pone en tela de juicio la vida de los pacientes. En nuestro caso, la simulación se sitúa bajo un modelo de educación por competencias, acorde con las modalidades y a los requisitos que demandan las instancias gubernamentales que regulan la educación superior que exigen evidencias de lo aprendido $y$, con ello, el papel de las prácticas académicas (indicadores) en ambientes adecuados. En ese escenario, la simulación da respuesta al profesional que se promete educar bajo una educación atenta a resultados del aprendizaje verificables. 



\section{La simulación en salud: una estrategia de evaluación y formación por competencias}

Claudia Espinal Correa

Carlos Andrés Álvarez Zuluaga

Jorge Humberto Rubio Elorza

Mauricio Vasco Ramírez 



\section{Acerca de los autores}

\section{Claudia Espinal-Correa}

Magíster en Gestión Tecnológica. Es líder nacional del proyecto Rizoma de la Dirección Nacional de Innovación y Tecnologías Educativas, Universidad Cooperativa de Colombia, sede Medellín, Colombia. Correo electrónico: claudia.espinal@ucc.edu.co

\section{Carlos Andrés Álvarez Zuluaga}

Tecnólogo en Atención Prehospitalaria. Es coordinador de Ambientes Prácticos de Aprendizaje de la Subdirección Académica, Universidad Cooperativa de Colombia, sede Medellín, Colombia.

Correo electrónico: carlos.alvarezzu@ucc.edu.co

\section{Jorge Humberto Rubio Elorza}

Anestesiólogo cardiovascular. Es médico especialista en Suramericana de Seguros.

Correo electrónico: jrubio@sura.com.co

\section{Mauricio Vasco Ramírez}

Anestesiólogo. Es profesor en la Universidad CES.

Correo electrónico: mvascor@ces.edu.co 


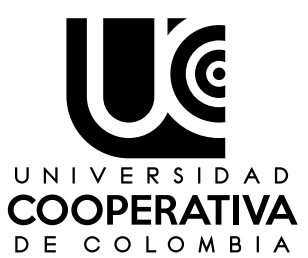

COOPERATIVA

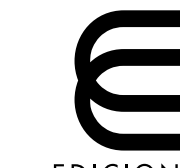

EDICIONES

Universidad Cooperativa de Colombia

\section{GREEN PAPERS}

La simulación en salud: una estrategia de evaluación y formación por competencias (c) Ediciones Universidad Cooperativa de Colombia, Bogotá, noviembre del 2021

(c) Claudia Espinal Correa, Carlos Andrés Álvarez Zuluaga, Jorge Humberto Rubio Elorza y Mauricio Vasco Ramírez

\section{Colección Green Papers}

D0I: https://dx.doi.org/10.16925/wpgp.04

\section{Fondo Editorial}

DIRECTOR NACIONAL EDITORIAL

Julián Pacheco Martínez

ESPECIALISTA EN GESTIÓN EDITORIAL

Daniel Urquijo Molina

ESPECIALISTA EN PRODUCCIÓN EDITORIAL (LIBROS)

Camilo Moncada Morales

ESPECIALISTA EN PRODUCCIÓN EDITORIAL (REVISTAS)

Andrés Felipe Andrade Cañón

ANALISTA EDITORIAL

Claudia Carolina Caicedo Baquero

\section{Proceso editorial}

CORRECCIÓN DE ESTILO

Guiovana Camila Suárez

DIAGRAMACIÓN Y DISEÑO DE PORTADA

Juan Pablo Rátiva González

Impreso en Bogotá, Colombia. Depósito legal según

el Decreto 460 de 1995

\section{(c) $(1) \circledast$




\section{Contenido}

Algunos aspectos conceptuales, de enfoque, implementación y norma

Aspectos de enfoque: la simulación en un Modelo Educativo Crítico con Enfoque de Competencias

Aspectos de implementación: la simulación y la evaluación

La simulación y su fortalecimiento a través de comunidades virtuales de aprendizaje y práctica

Conclusiones

Referencias 


\section{Índice de figuras}

Figura 1. Pirámide de Miller 30

Figura 2. Los nueve estilos de aprendizaje 35

Figura 3. El círculo del aprendizaje experiencial

Figura 4. Conceptualización abstracta y relación con Miller:

aprendizaje de los conceptos

Figura 5. Experimentación concreta: escenario para el desarrollo de destrezas

Figura 6. Experimentación activa: escenario de alta fidelidad

Figura 7. Observación activa: debriefing

Figura 8. Escala de la taxonomía solo

\section{İndice de tablas}

Tabla 1. Retícula rúbrica institucional ucc

Tabla 2. Datos globales de las Comunidades Rizoma de Aprendizaje en el diplomado "Evaluación por Competencias en Salud", Decanaturas Nacionales de Salud, Universidad Cooperativa de Colombia, 2018-2019 


\section{Introducción}

Oigo y me olvido. Veo y recuerdo. Hago y entiendo.

Confucio

T uestra institución tiene el compromiso ineludible de formar "sujetos competentes" a través de las competencias genéricas, transversales y específicas, declaradas en los planes de curso de los programas académicos en coherencia con nuestro modelo educativo crítico con enfoque de competencias. Esta responsabilidad demanda cambios radicales en la relación enseñanzaaprendizaje en un mundo de puertas abiertas, que cambia constantemente. Para ello, cuenta en su haber con la historia reciente del campo educativo, que relata grandes cambios en la didáctica, en la fundamentación de sus recursos, así como en los enfoques pedagógicos y en la multiplicación de recursos virtuales (como objetos virtuales de aprendizaje [ova], por ejemplo), en el aumento progresivo de la virtualidad bajo diferentes modalidades, la proliferación de plataformas tecnológicas; además de la aparición de decretos y normas que ajustan la educación superior a demandas internas y externas en consonancia con los avances y nuevas apuestas de los sistemas de aseguramiento de la calidad. En general, se trata de estar a tono no solo con lo que sucede en el país, sino con lo que se acontece en el planeta.

Desde esa perspectiva, la simulación como campo conceptual, práctico y pedagógico brinda un sinnúmero de posibilidades para la formación educa- 
tiva en general, y para currículos por competencias en particular. Su potencia específica para las áreas de la salud radica en que permite entrenar antes de hacer directamente en el cuerpo del otro: equivocarse sin dañar, mirarse en el actuar y encarar a la autocrítica como parte vital, ética (en el plano del Ser y la toma de decisiones haciéndose responsable de las mismas), en el proceso de aprendizaje.

La responsabilidad que tiene la Universidad Cooperativa de Colombia (UCC) implica dotar a los futuros profesionales y especialistas de las ciencias clínicas con las competencias necesarias para trabajar con los desajustes del cuerpo de manera efectiva. Esto exige mirar al futuro y salir de la prisión que suponen las urgencias del presente, toda vez que, en la actualidad, hay evidencia cada vez más robusta acerca de los beneficios del desarrollo y el mantenimiento de las habilidades y destrezas psicomotrices y cognitivas del personal de la salud, a través de la simulación como estrategia transversal en los procesos de formación. Esto le permitiría convertirse en un modelo sostenible a largo plazo y con ventajas contundentes tanto para los pacientes como para los sistemas de salud en el mundo.

Bajo esa perspectiva, este libro aporta la dicha intención, en parte como fruto de la experiencia y materialización de largas discusiones conceptuales y su objetivación práctica acerca del papel de la simulación en las ciencias de la salud de la UCC, proceso que iniciamos en el 2011 dentro de la estructura organizativa que, para el 2013, se convirtió en la Decanatura Nacional de Medicina. Algunos de los frutos aportados por este equipo se inscriben no solo en este libro, que se fundamenta en dicha experiencia $y$, de hecho, la actualiza, sino en el aporte en otros ámbitos como el diseño conceptual y de infraestructura de laboratorios, articulado a un plan de capacitaciones al profesorado, bajo un plan general anual de auditorías de acompañamiento y verificación interna de cumplimiento de objetivos y prácticas, adscritas a los laboratorios (lo que 
hoy podría ser equiparable en parte a una de las evidencias de seguimiento de los resultados del aprendizaje; igualmente, la adopción de nociones claras (el para qué) que anteceden la adquisición de equipos. Lo anterior como un todo acoplado, como un dispositivo con el que abordamos el diseño y prospectiva de los laboratorios de simulación clínica de las sedes de Medellín, Santa Marta y Pasto. Todos estos son aspectos que también fueron aplicados para el diseño del laboratorio de biología molecular -campus Medellín- bajo rigurosos estándares de la norma Iso 9001 y cuyos frutos se recogieron en el 2020, cuando en razón de ello fuera certificado por el Instituto Nacional de Salud para la prestación de servicios como la toma de muestras y procesamiento para detección del virus SARs-CoV-2. Una rigurosidad que también acompañó a la ideación, al diseño y a la materialización de los laboratorios multifuncionales, que además se construyeron bajo el concepto de "circuito de aprendizaje", experiencia cuyos desarrollos y actualización recogidos en este libro se convierten en el cimiento sobre el cual seguir mejorando, profundizando, complementando o interpelando lo que aquí se dice bajo el emplazamiento de la argumentación y no de la opinión, dado que nada está acabado de antemano, y justo la academia es el lugar para discernir, como premisa para avanzar y contribuir así a una simulación bajo una visión de futuro.

Se trata de un bagaje conceptual, técnico, instrumental, tecnológico, de infraestructura, sentido de las capacitaciones, perfil de personal, gestión y administración, entre otras que, a la luz del presente, fundamentan este aporte a la institución. No se trata de un documento histórico y anecdótico, sino más bien de la historia proyectada a un presente que nos define y al futuro que nos pregunta: ¿qué tipo de universidad queremos ser? Pretendemos tender puentes, ineludibles entre la formación en las áreas de la salud, las bondades de la simulación como metodología y estrategia de enseñanza y de evaluación, en el cambio de enfoque, que exige asuntos tan trascendentes como la formación por competencias (modelo pedagógico declarado en nuestro Proyecto 
Educativo Institucional [PEI]), la seguridad del paciente y por qué no, como alternativa para el desarrollo de hospitales simulados que tengan a cargo el desarrollo del mapa completo de habilidades y destrezas declarados en los programas de curso por competencias en áreas de la salud. Esto último en el marco de las restricciones que supuso, por ejemplo, la rotación por centros asistenciales (parte sustancial de la delegación progresiva requerida por norma ministerial) ante la pandemia por Covid-19.

El presente libro está estructurado de tal manera que, partiendo de un horizonte conceptual, nos podamos encontrar con el lector para encarar un horizonte de sentido, sea para avalarlo, controvertirlo o ampliarlo, todas tareas académicas de envergadura. Posteriormente, dilucidamos, desde nuestra experiencia académica en la UCC, la relación de la simulación con el enfoque de competencias del modelo educativo en el cual ella se encuentra inmersa, es decir, situamos la práctica de la simulación, le damos un contexto desde la formación y la evaluación por competencias. Más adelante, ubicamos la simulación a la luz de aspectos normativos del Ministerio de Educación Superior en Colombia, particularmente, el Decreto 1330 [1], pues uno de sus pilares se sostiene en los llamados resultados del aprendizaje, interrogándonos acerca de cómo con esta práctica contribuimos a su consecución, para concluir que no es más que a través del logro de la competencia en nuestros estudiantes. Abonamos también un apartado donde denotamos el papel de comunidades virtuales de aprendizaje y práctica como nodos de discusión y consensos a la hora de dar respuestas a los interrogantes que la simulación plantea. Finalizamos con unas conclusiones que recogen el Saber, Ser y Hacer armonizado que la simulación ha tatuado en quienes escribimos estás páginas.

En el presente libro, la articulación de estos componentes resulta que llama a su discusión y apropiación, también a su mejora, dado que la educación no es un fin, sino un medio que se enfrenta con la realidad de un sistema dinámico y cambiante: la educación. 



\section{ALGUNOS ASPECTOS CONCEPTUALES, DE ENFOQUE, IMPLEMENTACIÓN Y NORMA}




\title{
Aspectos conceptuales
}

\begin{abstract}
uando hablamos del aprendizaje de una disciplina, inevitablemente nos remitimos a la pedagogía. No vamos a disertar sobre escuelas, enfoques o su historia, pero sí es válido declarar que ha habido tránsitos importantes que van de la pedagogía de la enseñanza a la pedagogía del aprendizaje y que hoy se asienta en la relación que se desata justamente en el proceso enseñanzaaprendizaje. Un asunto que también atraviesa la didáctica (entendida como el manejo de todos los elementos y recursos que intervienen y hacen posible el aprendizaje, es decir, como mediación pedagógica), pudiéndose hablar, entonces, de una basada en la forma en como el sujeto aprende, lo que implica una transformación en los roles que ha de cumplir el profesor proyectándolo como facilitador, asesor, acompañante del proceso, apoyado en recursos dinámicos, interactivos y problematizadores del saber.
\end{abstract}

En ese análisis, la simulación emerge como estrategia pedagógica (parte de una pedagogía). En este contexto, el concepto de simulación clínica surge en 1966 [2], cuando se encuentran dos disciplinas dispuestas a conversar: la medicina y la ingeniería, representadas por los doctores Stephen Abrahamson (ingeniero) y Judson Denson (médico). A partir de sus conversaciones, nace el primer simulador para la enseñanza de la intubación orotraqueal dirigido a los estudiantes de anestesiología en California.

La estrategia de la simulación clínica como parte de una pedagogía adscrita a centros de simulación en las instituciones educativas o centros clínicos ha de 
entenderse como una práctica educativa previamente planeada en lo pedagógico, lo didáctico, lo instrumental y a nivel de ambientes de aprendizaje. Es un plan, una planeación, en el marco del desarrollo de capacidades en contexto y de la acción sobre casos clínicos complejos; todo ello como contribución al logro de las competencias que el currículo establece. Esta estrategia pone en cuestión el modelo meramente instruccional que se enfoca en buena parte en la adquisición del Saber y más bien sitúa al aprendiente en la zona del Saber-Ser-Haciendo: parte de una serie de escenarios simulados problematizados, lo más próximo a lo real sin sustituirlo, insertado dentro de la malla curricular, con un propósito académico preciso (logro de la competencia) donde debe encarar una decisión, para luego reflexionarla de manera autocrítica y, de este ejercicio sistemático, al final emerge un profesional mejor dotado para enfrentar los desafíos y la incertidumbre del mundo del trabajo. La simulación problematiza el saber con casos, permite el error y la autocrítica, ese poder devolverse en las decisiones o acciones efectuadas sin haber dañado, lo que conlleva al desarrollo de un fuerte componente actitudinal (en el marco de las competencias del Ser), que nace de esa relación enseñanza-aprendizaje, mediante la práctica simulada analizada por el sujeto que la pone en marcha, pues cada sujeto no es un balde vacío, él deviene de un lugar desde el cual enuncia, desde donde asume el aprendizaje: los marcos mentales.

La práctica de la simulación devela, justamente, los marcos mentales previos desde donde el sujeto aprende, con la posibilidad de transformarlos por ese efecto espejo de verse a sí mismo ejecutando decisiones sobre el cuerpo simulado del otro, y que lo hacen responsable frente a su quehacer; actitud crítica cuyo ejercicio determinará gran parte del desempeño profesional futuro. Como bien lo expresa Dieckmann: "Mediante la exploración de los modelos mentales detrás de las acciones, a través del intercambio de opiniones abiertamente en una conversación constructiva y con sentido, los participantes y facilitadores pueden construir en forma conjunta un aprendizaje reflexivo que permita un aprendizaje más profundo" $[3, \mathrm{p} 4]$. 
Problematizar los modelos mentales prefijados con los que los aprendientes llegan a la práctica educativa va más allá de códigos morales personales, y cuya reflexión en el escenario simulado, “¿qué estoy haciendo mal?”, conlleva la reducción de las malas prácticas profesionales futuras, hoy en boga. Igualmente, estos escenarios, al simular los ambientes de atención sanitaria, promueven una condición de respeto, de validación del trabajo interdisciplinario, que implica una jerarquía de responsabilidades (solo en función de mantener la vida), lo que no impide una acción reflexiva y horizontal, más en aquellas disciplinas donde el propósito es salvar la vida del paciente porque lo contrario atenta contra el bienestar de aquellos a quienes se cuida.

Desde esta perspectiva, Amaya menciona que:

La simulación clínica es una estrategia pedagógica y evaluativa que se ha desarrollado de manera vertiginosa desde mediados del siglo xx y está siendo considerada con mucha importancia dentro de los currículum de medicina debido a su utilidad en el desarrollo de las competencias profesionales del médico, al cambio de paradigma en el cual se deja de centrar la educación en la enseñanza y pasa a centrar su atención en el aprendizaje y la consideración que se tiene de la simulación en la actualidad, como un criterio de calidad educativa. [4, p1]

Esta es una estrategia que favorece la seguridad del paciente, en tanto supone entrenamiento instrumental, material, mental, autocrítico y de responsabilidad previo, cobrando relevancia el Saber-Ser-Haciendo.

La simulación es un Hacer que merece la estimación de unos tiempos para su desarrollo, listas de chequeo que explicite lo que el estudiante debe lograr (la competencia), curvas de aprendizaje que delimiten los tiempos promedio de ejercitación en una práctica para lograr la habilidad(es) propuesta(s), simuladores para el ejercicio, ambientes de aprendizaje adecuados y un caso donde se justifique la toma de decisiones y de cuenta de los aportes previos 
del entrenamiento en destrezas más simples(escenarios simulación alta fidelidad). En suma, una concatenación de eventos planeados y argumentados, como indica Unigarro:

En la enseñanza hay que seguir la dinámica propia de la naturaleza, esto es, entre otras: actuar en el momento oportuno, ir paso a paso, sin saltarse ninguno; tomarse el tiempo para la preparación; operar de adentro hacia afuera y no abandonar hasta haber completado la operación. [5, p109]

\section{Aspectos de enfoque: la simulación en un Modelo Educativo Crítico con Enfoque de Competencias}

Según Zabalza, "la principal innovación metodológica en los últimos años ha sido trasladar el centro de atención de la enseñanza al aprendizaje" [6, p237]. Nuestro Modelo Educativo Crítico con Enfoque de Competencias afirma que su corazón se ubica en la relación que se establece entre quien enseña y quien aprende, en tanto que dos subjetividades se encuentran y cuyo desafío radica en lograr un horizonte interpretativo cercano, bajo unos acuerdos y unas reglas de argumentación y respeto mutuo. En resumen, llama a una construcción colectiva encaminada al logro de las competencias bajo las demandas del contexto, y un ambiente apropiado para su aplicación. Sobre esto, Unigarro afirma: "Esta faceta de la articulación tiene que ver con la pertinencia, con la enseñanza contextualizada. Esto hace que se elimine la fractura entre la universidad y la sociedad, la escisión entre la academia y la realidad" [4]. De esta manera, el proceso de educar interpela a una transformación sustantiva del concepto de enseñanza y de la función atribuida a profesores y alumnos en su transcurrir por el proceso educativo.

Podemos afirmar que la formación profesional basada en competencias, hacia el logro de habilidades y destrezas como consecuencia del Saber-Ser-Haciendo, implica un nuevo diseño curricular donde lo relevante es que el futuro pro- 
fesional demuestre y autoevalúe lo que puede hacer en el escenario simulado antes de enfrentarse al mundo real. Por ello, el desempeño se certifica mediante la aplicación de instrumentos como la rúbrica, que den cuenta del estado de desarrollo de la competencia en el estudiante, de su avance, del logro.

El Saber-Ser-Haciendo, en los cánones de la educación en ciencias de la salud y del mundo de hoy, remite a un currículo por competencias, entendidas como aquello que:

No se refiere a la formación de mano de obra barata, ni a garantizar buenos empleados y mucho menos confunde personas competentes con competidores [...] un modelo educativo crítico con enfoque de competencias [...] trata de educar para el Mundo de la vida, que es el mundo en el que se trabaja. El trabajo es la manera como las personas completan su desarrollo, es una forma de ser y de estar en el mundo [...] la competencia es la armonía de lo lógico, lo ético y lo estético, es el movimiento armónico de los conocimientos, las actitudes y las habilidades y destrezas. En ese sentido, este modelo busca seres competentes, no competidores. El competidor es contendor, el competente es solidario. [5, pp11-12]

Bajo esta declaración sobre las competencias, que asumimos a lo largo de este texto, se entiende el desempeño del futuro profesional como una experiencia integrativa y no como componentes fragmentados y por fuera de contexto. Así visto, lo importante no es la adquisición de determinados conocimientos, sino el uso eficaz y oportuno que se haga de ellos; conocimientos que se pueden problematizar en escenarios simulados: casos clínicos, protagonizados por "pacientes" actores con patologías estandarizadas y protocolizadas, puestos en ambientes de consulta donde el estudiante debe poner en acción su conocimiento teórico, sus acciones éticas y su pericia procedimental; es decir, la resolución de un caso que integre acertadamente el componente básico con el clínico bajo una guía que precisa la competencia a lograr (habilidades y destrezas) $y$, al final, una mirada introspectiva y puesta en común con los profesores y compañeros observadores del proceso, que permita verse a sí 
mismo con el único y tenaz propósito de mejorar; es decir, lo que en términos técnicos se denomina un debriefing: verse en acción con otros y ante otros en forma horizontal, poner en común, profundizar en las causas relevantes de lo que aún no se logra y establecer estrategias de logro. Allí, el rol del docente no es calificativo ni enjuiciador, sino horizontal y de facilitador del proceso; en otros términos, es lo que llamaremos una "evaluación formativa", como bien lo refiere Maestre [7].

Ahora bien, la simulación en el terreno de las competencias se introdujo en los propósitos de la enseñanza hace más de 50 años, como lo señala Matiz: "En la simulación, el estudiante no va a trabajar directamente con el objeto de estudio (el paciente), sino con una representación de dicho objeto (modelos, maniquíes o computadores), de tal manera que la simulación supone la elaboración de modelos" [7, p299]. Bajo esa premisa, la simulación está enmarcada en el campo de la didáctica, ya que permite "la modelación o enseñanza por modelos o por maniquíes; es un nuevo método científico por medio del cual se puede ampliar el conocimiento" [7, p299].

La implementación de la simulación, en el área de la educación médica, consiste en poner al estudiante en un ambiente que emule algún aspecto posible de su real práctica médica, en el marco del pacto de ficción y los acuerdos de confidencialidad respectivos; dicho de manera coloquial: "Lo que pasa en Las Vegas, se queda en Las Vegas". Este pacto es la premisa previa a la experiencia simulada, que demarca, en términos prácticos, el clima de confianza explícito para afrontar los escenarios simulados, para hacer del error no un comentario, un arma, sino fuente de mejora, capacidad de autorreflexión y autorregulación.

Como bien se ha definido en otros ámbitos, las estrategias, en este caso educativas, se acompasan con desarrollos teóricos, técnicos y tecnológicos y la simulación no es ajena a esto. Está inmersa en el área de desarrollo de los simuladores, por ejemplo, herramientas que fijaron su aparición, modelado 
y avances hacia aquellos que cada vez más se asemejen a la organicidad y funcionalidad del cuerpo humano, para poder convertirse en instrumentos técnicos, que harán parte de la problematización del saber ser haciendo. En tal sentido, un hito importante en la aparición de la simulación, en el marco de su potencia para el logro de destrezas, remite a la década de 1960 con la introducción de "Resusci Anne ${ }^{\circledR}$ " (simulador propuesto para reanimación) y de "Harvey ${ }^{\circledR}$ " (un simulador de tamaño real fabricado para entrenamiento en ruidos cardiacos). Como indica Cooper, "en un estudio realizado en los ochenta con 208 estudiantes de medicina entrenados con 'Harvey' mostraron mayor habilidad en la realización correcta de la evaluación cardiaca y un mayor sentido de confianza en sus capacidades" [2].

A finales de la década de 1990, se introdujeron simuladores de pacientes humanos, portátiles, anatómicos, cómodos en su manejo e instalación, lo que transformó la educación en salud, poniendo a disposición nuevas tecnologías de la información y la comunicación para hacer al futuro profesional más competente y evaluar, en esta misma dirección, la educación médica.

Las ventajas ya declaradas y estudiadas en el uso de simuladores en la educación en ciencias de la salud abundan en publicaciones, congresos, foros y talleres de corte mundial, como sostiene Matiz:

La simulación tiene también como propósito ser un auxiliar poderoso para la intuición porque se sale del marco real a lo virtual y ayuda al estudiante a comprender el peso enorme de tomar decisiones en el mundo real, es decir, ayuda a la modelación de los futuribles o de los futuros posibles de una realidad. [8, p299]

Un rastreo de dichas ventajas permite concluir que la simulación permite:

a) Optimizar la calidad de atención, resguardando el derecho del paciente a ser utilizado en docencia sin autorización. 
b) Contribuir a elevar la calidad profesional.

c) Permitir la utilización del error como un medio de aprendizaje. Hecho fundamental, y el costo ya no es de vidas humanas.

d) Problematizar situaciones simuladas introduce nuevos enfoques y contenidos:

La simulación permite un entrenamiento consistente y programado en numerosas situaciones clínicas como son patrones de presentación poco habituales o enfermedades raras, todo tipo de procedimientos, manejo de situaciones críticas y detección de situaciones potencialmente catastróficas. El proceso y la estructura de la educación médica se convierten así en una serie de elecciones progresivas por parte de los docentes, y no en una respuesta a las disponibilidades clínicas del momento. [9]

Dicho lo anterior, se afirma que la simulación potencia la respuesta en situaciones reales porque hay un entrenamiento previo que permite la manipulación práctica de objetos, simuladores o pacientes estandarizados con una problemática ante la cual el aprendiz forja una respuesta. En esta línea, desarrollar habilidades y destrezas presupone un fuerte componente en el entrenamiento práctico, reforzado por conceptos como el de Gorman et al.: "Por competencia profesional se entiende el conjunto de conocimientos y capacidades que permiten el ejercicio de la actividad profesional conforme a las exigencias de la producción y el empleo" [10, p354].

Con lo expuesto, podemos afirmar que los currículos por competencias, en general, deben dar cuenta, entre otras, de:

a) Incorporar de manera crítica las tendencias globales de la educación en salud. 
b) Sumar normativas externas de los entes gubernamentales y particulares, dado que amplían la visión sobre la simulación y le dan contexto de realización.

c) La conciliación práctica entre objetivos académicos, propósitos sociales y componente técnico e instrumental.

d) Compatibilidad con estándares internacionales de acreditación, que permitan la movilidad y la competitividad global, la homologación sin pérdida de identidad.

e) El desarrollo de perfiles profesionales explícitos de acuerdo con las condiciones sociopolítico-culturales de los países, de tal manera que su Ser competentes ayude en la mejora de las condiciones de vida de sus pueblos.

f) Un fuerte componente ético, que conlleve la reducción de las malas prácticas médicas, hoy en boga, pero que, ante todo, promuevan una exacerbación del respeto, la tolerancia, porque lo contrario atenta contra el bienestar de aquellos a quienes se cuida.

g) Programas de capacitación y entrenamiento para los docentes en el área de competencias, didácticas de aplicación y ambientes e instrumentos para su evaluación.

h) Cambios en la infraestructura física: creación de estaciones o circuitos de aprendizaje, prácticas de laboratorio sujetas a resolver problemas específicos, creación o ampliación de laboratorios de simulación, interacciones virtuales en tabletas interactivas, aprendizaje basado en problemas, gamificación, casos clínicos y la aplicación modelos de evaluación formativa.

En lo que sigue, vamos a analizar con detenimiento los numerales $f$ y $g$.

Si la educación tradicional en salud fundamenta su poder en un fuerte componente teórico, sin el suficiente entrenamiento experiencial en el que sea 
posible cometer errores sin dañar, el Saber se alejará del aforismo hipocrático "primum non nocere" ("antes que todo no dañar"), colisionando en algún punto con esta regla de oro, pues bajo estas condiciones de un menguado componente experiencial puede resultar en el deterioro de la calidad de la atención ofrecida al usuario del servicio de salud, al realizar un determinado procedimiento con una complejidad significativa (como intubar en urgencias o atender un parto en el comienzo de su quehacer profesional). Si a ello le sumamos el crecimiento exponencial de las demandas por mala práctica médica y, con ello, los portales web de organizaciones, federaciones, asociaciones donde se agrupa gente del común bajo la denominación de "víctimas de las malas prácticas médicas", sabremos que estamos frente a un panorama que pide reformular la preparación sanitaria, del personal en los centros asistenciales, dado que, como lo expresa Maestre et al.:

Mientras que la experiencia es la base para el aprendizaje del adulto, la teoría del aprendizaje de Kolb muestra que este no puede acontecer sin una «reflexión rigurosa». Es decir, tener experiencia no equivale necesariamente a ser experto. Por «reflexión rigurosa» se entiende un proceso que ayuda a revelar y resolver los dilemas clínicos y de comportamiento, y las áreas de confusión que surgen después de enfrentarse a un caso clínico. El aprendizaje es un proceso que comienza al enfrentarse con una situación que no se resuelve plenamente con los recursos utilizados habitualmente. La persona, motivada por una sensación de incertidumbre e incomodidad, busca examinar su experiencia: ¿cuál era la naturaleza del problema? ¿Cuáles eran sus intenciones? ¿Qué hizo? ¿Qué aconteció? [7. pp218-219]

Cabe comentar que la estandarización, en el sentido de cuánto es el tiempo y el número de prácticas o ensayos necesarios para alcanzar la técnica requerida para llevar a cabo un determinado procedimiento, o curva de aprendizaje, hace parte del planteamiento integral de la simulación anclada al currículo. En ese sentido, estas se convierten en un ejercicio riguroso, que permite plantear estos tiempos mínimos promedio de manera acertada y, con ellos, fijar la base 
para desarrollar las guías de práctica en las horas del trabajo independiente del estudiante en los laboratorios de simulación.

Hacer competente a un aprendiz del área clínica y salud implica evaluar el grado de competencia alcanzado, lo que nos enfrenta con el interrogante de cómo evaluar, medir, verificar las competencias diseñadas en los planes de estudio en salud y es allí donde la simulación en salud nos abre otro abanico de posibilidades. Sin duda, la responsabilidad que supone la dotación en los futuros profesionales de la salud de las competencias necesarias para su práctica profesional implica asimilar las urgencias del presente, nadar en las aguas de los enfoques teóricos ya diseñados y estructurados, pero también navegar con una visión pragmática que nos dote de las herramientas para que ello sea posible.

El enfoque por competencias ocupa hoy un lugar central y su conceptualización hace referencia, entre otras, a un Saber hacer para lograr un desempeño eficiente y medible, mediante acciones observables y evaluables. Dicho desempeño está centrado en desarrollar destrezas potenciando las condiciones que el estudiante trae para resolver problemas de manera flexible, en tanto tiene en cuenta las fortalezas individuales en directa relación con las demandas del medio interno y externo, presuponiendo cualidades adaptativas a situaciones diversas.

\section{Aspectos de implementación: la simulación y la evaluación}

Sobre este punto se ha discutido mucho, dando lugar a escuelas, corrientes y posturas que profundizan en su concepción e implementación. El propósito de este libro no es entrar en las discusiones que este campo tan vasto y complejo ofrece, pero sí se pretende mostrar cuáles son las bondades de esta estrategia a la hora de evaluar el aprendizaje en el marco de un currículo por competencias. 
Un apoyo conceptual importante a la hora de resolver el interrogante de cómo evaluar por competencias en las ciencias de la salud, lo encontramos en Miller [10], quien propone la llamada pirámide del aprendizaje y sobre cuya comprensión se puede erigir el qué, el cómo y el para qué evaluar (figura 1). En ella hay cuatro niveles de formación en orden de complejidad:

Figura 1. Pirámide de Miller.

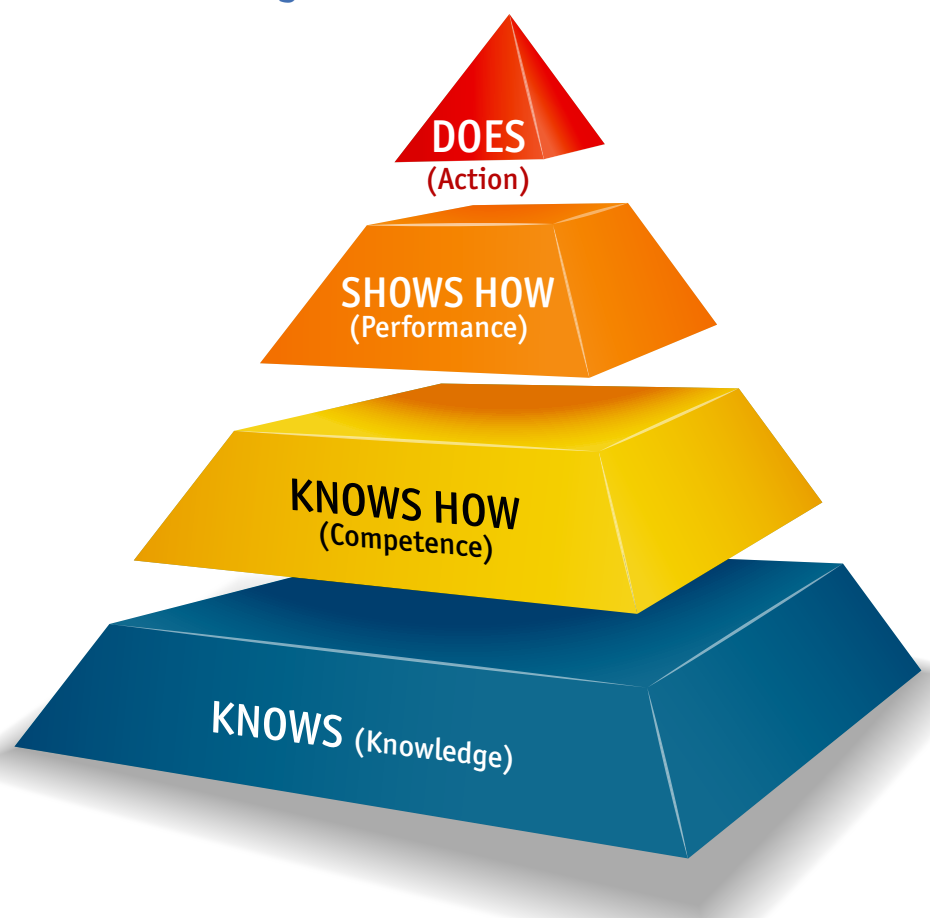

Fuente: tomado de Miller [11].

En la base de la pirámide: SABE (recuerda), reposan los conocimientos que un profesional necesita saber para desarrollar las competencias propias de su disciplina con eficacia; allí opera la memoria con valor significativo, en este caso, lo relacionado con su profesión como eje central. En el segundo nivel: SABE Cómo (competencia), se tiene en cuenta la habilidad para integrar e interrelacionar las disciplinas que confluyen en el saber propio de su profesión, asunto que en algunos planes de estudio en salud quedó materializado en la integración básico-clínica a lo largo de los contenidos. El tercer nivel, DE- 
MUESTRA Cómo (lo hace), se refiere al campo de lo práctico, la forma, el cómo asume e interactúa plenamente y sobre los hechos con su objeto de estudio, en nuestro caso, con el cuerpo el otro como totalidad fisiológica, orgánica, emocional, cultural y social. Dicho esto podemos señalar con certeza que una gran herramienta para valoración de dicho aprendizaje entendido sobre la premisa milleriana lo constituye la simulación con pacientes estandarizados y la práctica del debriefing al final de un circuito de aprendizaje: el escenario no es real, pero entrena para hacerle frente a los desafíos que la profesión propone, pone a prueba y corrige, permite que el sistema de aprendizaje y enseñanza se autocorrija, porque justo el debriefing llama a las reflexiones sobre sí mismo, es decir, el modo como operamos técnicamente, como actuamos con otros, cómo y qué decisiones tomamos y, la forma como llevamos a cabo, como maestros, el proceso de enseñanza

Finalmente, el nivel superior, HACE (acción), permite identificar la competencia alcanzada para saber cómo analizar y valorar los datos, cómo interactuar, cómo dar respuestas inmediatas y bajo presión, porque no solo es preciso conocer o saber utilizar, sino que también es necesario demostrar cómo y cuándo se utiliza. Aquí cabe otro escenario para las ciencias de la salud como verificador de muchas de las competencias logradas a través de cursos por competencias allanados y otras que se establecen justo en las rotaciones clínicas, con pacientes reales y en tiempo real.

Con base en lo dicho anteriormente, ratificamos a la simulación y sus escenarios como un ambiente de aprendizaje para la evaluación por competencias porque permite evaluar sin dañar. Esta evaluación, entretejida con el planteamiento milleriano y la rúbrica para medir el logro de la competencia, estructurada bajo el enfoque de la taxonomía solo, abre un campo de posibilidades que permite valorar de manera acoplada y armónica los elementos del saber-ser y hacer: medir el estado de desarrollo de la competencia en el 
marco de los resultados del aprendizaje, lograr un estudiante competente que no es más que la promesa de valor pactada no solo con los estudiantes, sino con sus familias, con la región y el país.

En lo que sigue, nos detendremos un poco más en esos aspectos que se irán articulando en pro de continuar aproximándonos al concepto de evaluación con peso conceptual, marco de reflexión y su inserción en el currículo por competencias.

\section{La evaluación con simulación: Miller y el Círculo del Aprendizaje (Kolb)}

En consonancia con lo anterior y acorde con nuestra práctica educativa, nos propusimos algunos referentes teóricos adicionales que se articularan con y robustecieran el Modelo Educativo Crítico con Enfoque de Competencias, una simulación con un fuerte componente conceptual, una intención práctica delimitada y explicitada a la luz de las demandas internas y externas y unos ambientes prácticos debidamente formulados y dotados que pudiesen generar buenos resultados en el estudiante y transformaciones pedagógicas y prácticas en el profesor. Esto último en razón de que en el profesorado que hace simulación en los centros de educación superior se observa diferentes niveles de conocimiento, profundidad y manejo práctico (novatos-intermedios y expertos), asunto a tener presente por el impacto desafortunado que puede significar en el proceso de enseñanza.

Una vez descrita la pirámide de Miller (figura 1), cabe resaltar la coherencia y fuerza de cada momento evaluativo alimentado y enriquecido con diversidad de estrategias implementadas durante los momentos de la enseñanza. Es decir, será importante armonizar las estrategias del cómo evalúo al estudiante para que correspondan con el cómo se le ha enseñado dado que en la práctica 
se observa algunos profesores que sin entrenamiento previo usan escenarios de simulación clínica para evaluar estudiantes que, hasta el momento, solo se habían visto inmersos a la estrategia de clases magistrales en el aula, generando en el aprendiente ansiedades innecesarias y cuestionamientos sobre la efectividad de esta estrategia cuando no tiene una articulación clara con el aprendizaje y la evaluación, dando como resultado el temor del estudiante al trabajo dentro del laboratorio. El acto de enseñar deberá estar impactado por las complejidades que propone el proceso de aprendizaje, tema que hoy en día cuenta con infinidad de fuentes, propuestas, análisis e investigaciones y que desde luego su conocimiento enriquece dicho proceso y prepara y realimenta la estrategia de la simulación: asumir el aprendizaje como una experiencia vitalista donde todos y todo se transforma, reconocer patrones de aprendizaje, darle a los instrumentos y tecnologías que llenan los ambientes de aprendizaje el carácter de dispositivos que alinean en su uso una intención pedagógica, abstraer como esto y otros elementos conjugados interpelan, deberían, el acto generoso de enseñar y de evaluar, pues ambos son las caras de una misma moneda.

En ese sentido, entremos a valorar la propuesta de vinculación de la teoría experiencial y el Círculo de Kolb del aprendizaje, con la propuesta de Miller para evaluar la competencia. En su libro Learning Style Inventory, David A. Kolb habla de la teoría del aprendizaje experiencial (ELT, por sus siglas en inglés), la cual "se basa en el trabajo de destacados académicos del siglo xx que le dieron a la experiencia un papel central en sus teorías sobre el aprendizaje y el desarrollo humano" [17, p6]. Kolb encuentra cómo estas llamadas "experiencias" tienen un impacto diferente en cada persona, dependiendo de su estilo de aprendizaje, lo que permite establecer una interesante relación con los elementos de un escenario de simulación clínica, el cual pretende generar experiencias similares a la realidad de manera que se prepare a los estudiantes para un futuro desempeño en el campo de acción laboral en cuanto a sus habilidades técnicas y no técnicas. 
En la actualidad, es posible reflexionar sobre el papel que Kolb le otorga a la combinación de experiencias en el proceso de aprendizaje: "El conocimiento es el resultado de la combinación de captar y transformar la experiencia" [17, p7], pues antes de correlacionar los momentos experienciales en su famoso Círculo Experiencial, es importante mencionar que, para llegar a la combinación de estrategias experienciales, David y Alice Kolb [17] indican que no todas las personas aprenden de la misma manera. Aunque parezca una afirmación obvia, en su tiempo fue uno de los grandes aportes de los autores con la descripción de cuatro diferentes estilos de aprendizaje de manera que años después se llegaría a afirmar que "los estilos de aprendizaje originales (acomodatorios, asimiladores, convergentes y divergentes) se pueden refinar aún más en una tipología de nueve estilos que define mejor los patrones únicos de los estilos de aprendizaje individuales" [17, p13]. La figura 2 resume los diferentes estilos de aprendizaje descritos anteriormente.

Para la comprensión de la figura 2, introducimos a continuación unas definiciones [17]:

- El estilo iniciador: se ubica en el extremo superior derecho y se caracteriza por la capacidad de iniciar acciones para afrontar experiencias y situaciones. Implica experimentación activa (AE) y experiencia concreta (CE).

- El estilo analista: integra ideas en modelos y sistemas concisos a través de la reflexión. Combina observación reflexiva (RO) y conceptualización abstracta (AC).

- El estilo balanceado: se caracteriza por la capacidad de adaptación, sopeso de los pros y los contras, acción frente a reflexión; y experimentar frente a pensar. Equilibra la experiencia concreta, la conceptualización abstracta, la experimentación activa y la observación reflexiva. 
Figura 2. Los nueve estilos de aprendizaje.

\section{Concrete Expetience}
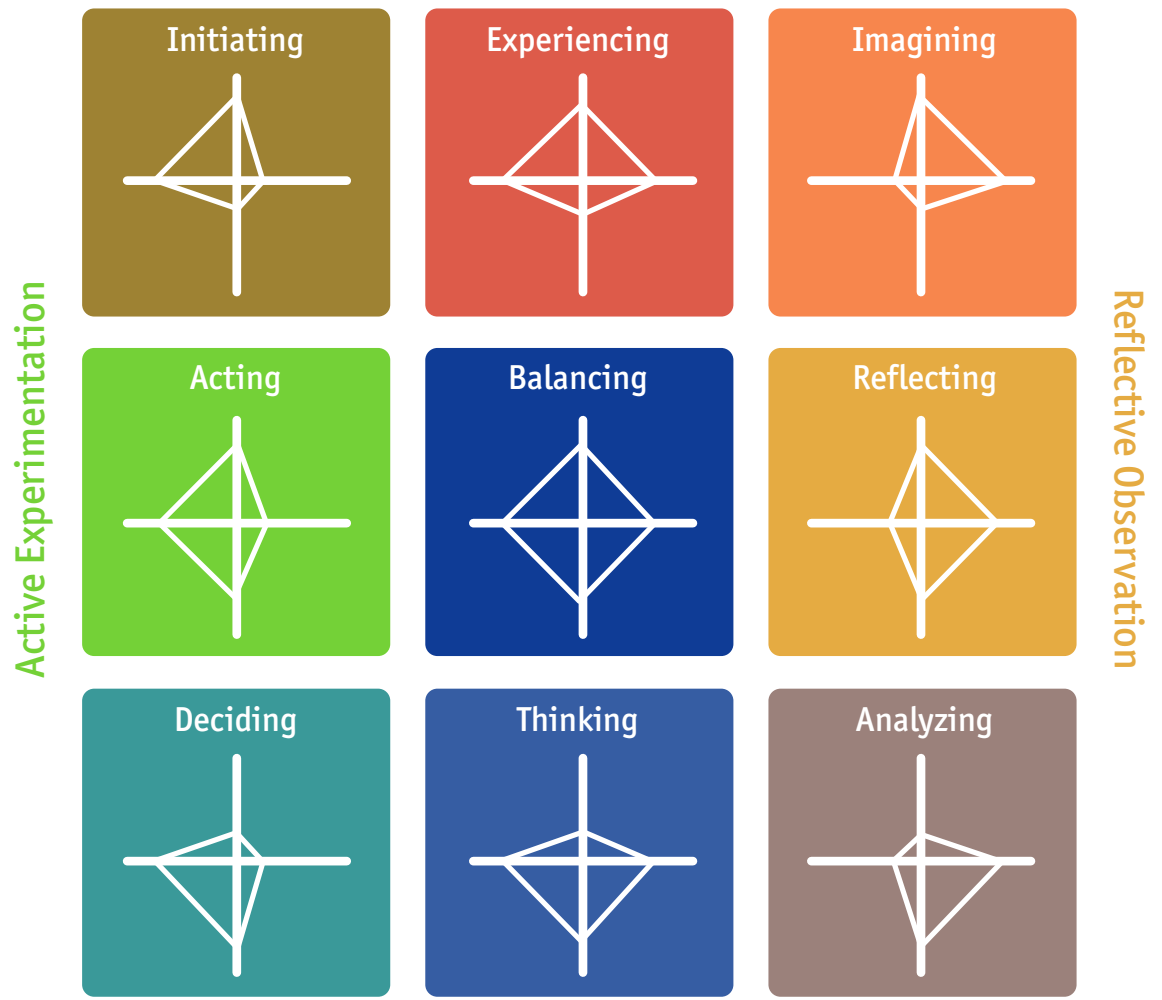

Abstract Conceptualization

Fuente: tomado de Kolb y cols. [17].

Como se detallará más adelante, el círculo del aprendizaje, a manera de plano cartesiano, acomoda un espacio de aprendizaje bidimensional donde se corresponden en el primer plano, la conceptualización abstracta (AC) frente a la experimentación concreta $(\mathrm{CE}) \mathrm{y}$, en el segundo plano, la experimentación activa ( $\mathrm{AE}$ ) frente a la observación reflexiva (RO), lo que nos implica pensar que el aprendizaje consiste en, una vez identificado un estilo, llevar al estudiante hacia aquel polo dialéctico que le permita equilibrarse con el que no es su estilo; por ejemplo, si un estudiante tiene como virtud un estilo favorecido por las actividades que fomentan la conceptualización abstracta (AC), significa que su plano de experiencia concreta deberá ser abordada con mayor énfasis 
en su proceso para que, a partir de este se pueda concluir que lo abstracto o la formación de conceptos también nace de la experiencia concreta.

Dicho de otra manera, si un estilo de aprendizaje en el estudiante se encamina más hacia elementos del saber disciplinar, en el marco de las competencias, el proceso de enseñanza-aprendizaje deberá dar cuenta de actividades que favorezcan el desarrollo de experimentación concreta (CE), que no es más que el desarrollo del elemento del Hacer, también en el marco de las competencias.

Ahora bien, gracias al aporte de los autores podemos abrir el debate y cuestionarnos sobre las estrategias que implementamos para trasmitir el conocimiento y evaluarlo, partiendo de la base de que no todos los estudiantes de un curso aprenden de la misma manera. Es común observar que la estrategia más utilizada por los profesores sin entrenamiento en simulación es replicar tal cual su estilo de aprendizaje sin cuestionamiento, lo que lleva a evaluar de un solo modo, dado que, parafraseando a Unigarro [5]: quien no cambia su manera de enseñar, no cambia su manera de evaluar.

Se pretende, entonces, advertir que si usamos diferentes estrategias para enseñar, debemos procurar una nueva forma de evaluar la rúbrica y es ahí donde los autores que participamos en este libro se deben poner a conversar para proponer, con fundamento, una estrategia evaluativa con diferentes tipos de experiencias, que permitan dar evidencia de una competencia. El hilo conductor que usa el profesor para entrelazar ambas propuestas teóricas (Kolb y Miller) es la estrategia de la simulación.

Kolb diseña una estrategia de enseñanza donde se combinan varios momentos formativos que pueden potenciar de manera equitativa los diferentes estilos de aprendizaje a través de diferentes tipos de interacciones, lo cual genera un recorrido lógico en que, de manera ordenada, los estudiantes podrán 
recibir las diferentes actividades planteadas por el profesor, que se espera permitan transformar la experiencia en conocimiento, que no es más que llevar al estudiante hacia el logro de la competencia en consonancia con su estilo de aprendizaje aproximándolo a otros.

La figura 3 ilustra la relación entre las actividades de aprendizaje-estilos de aprendizaje incluidos y da una ruta de cómo operativizarlos, por ejemplo: la AC combinarla con la CE y la AE con la RO.

Figura 3. El círculo del aprendizaje experiencial.

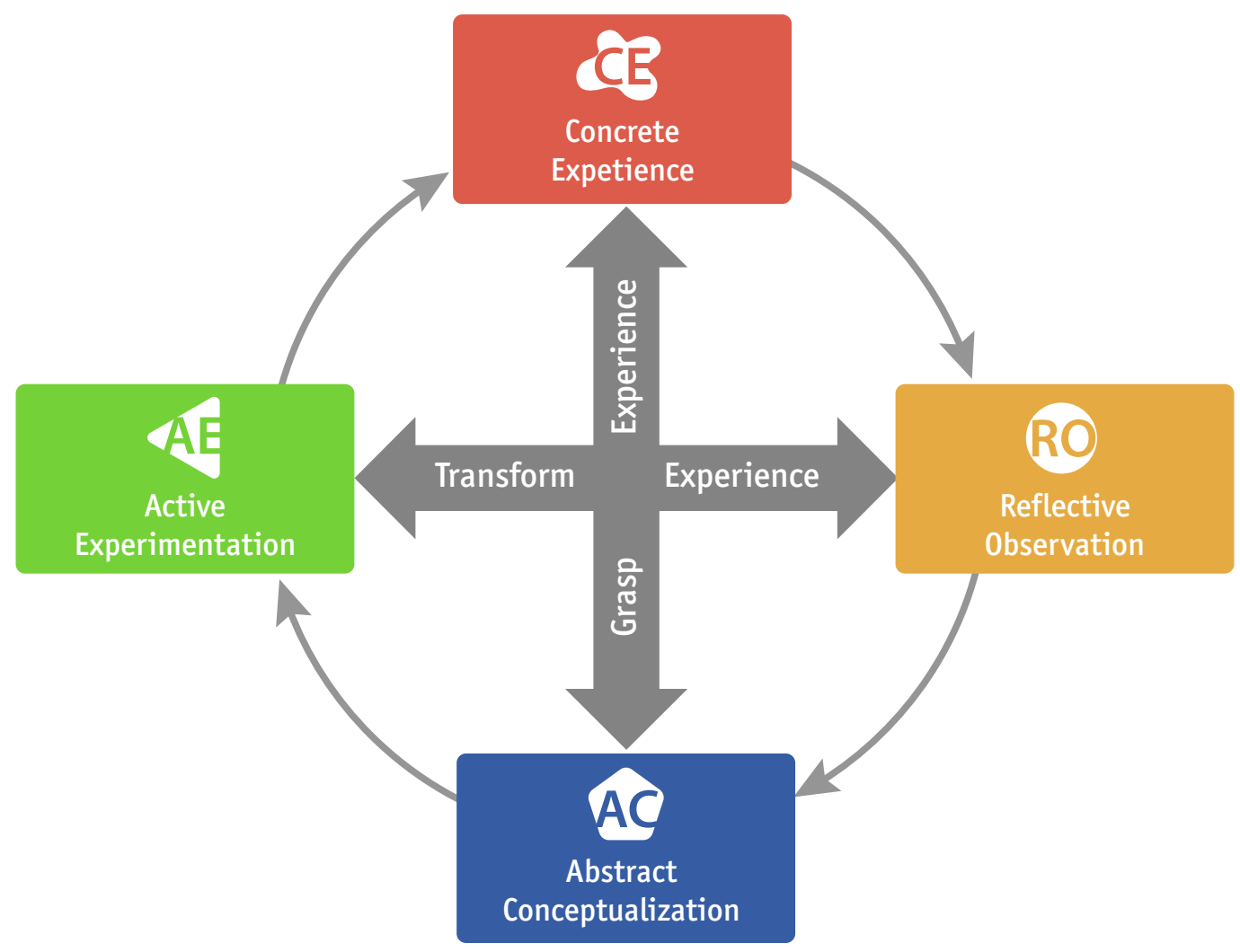

Fuente: tomado de Kolb y cols. [17, p8].

Hasta ahora hemos ilustrado, por un lado, el concepto de la enseñanza en Kolb permeado por estilos de aprendizaje y, por el otro, hemos conjeturado que la enseñanza no está al margen de la evaluación. Por ende, proponemos cómo la simulación es, al mismo tiempo, una estrategia de enseñanza y una 
evaluación que, bien diseñada, involucra los estilos de aprendizaje. Expresado esto, cabe la pregunta: ¿cómo articulamos enseñanza, evaluación y simulación? A continuación, se proponen una serie de actividades en el aula, laboratorio de simulación y virtualidad en relación con lo revisado en las teorías de Miller y Kolb. Para ello, partimos de proponer una serie de actividades en el marco del círculo del aprendizaje visto anteriormente.

\section{Conceptualización abstracta (Ac)}

En este momento, los profesores pueden generar actividades como clases magistrales, lecturas previas, envío de información e investigación sobre diferentes temáticas, las cuales incluyan las consultas en bases de datos, etc. Estas estrategias educativas le permiten al estudiante desarrollar un aprendizaje que favorezca los estilos del campo abstracto (figura 2).

\section{Conceptualización abstracta y relación con Miller, momento evaluativo}

Este momento experiencial se puede relacionar con la pirámide de Miller (figura 1) en su base de Saber (Know), pues se busca hacer evaluaciones tipo prueba escrita, las cuales incluyen todas las pruebas virtuales que busquen la evaluación del conocimiento mediante varios tipos de preguntas, entendiendo que su elaboración deberá contemplar una gama de ellas, que den cuenta de diferentes estados de desarrollo de la competencia en el elemento del Saber; por lo tanto, las preguntas deben permitir detectar niveles uniestructural, multiestructural, relacional o abstracto ampliado (taxonomía solo).

En línea con esto, se advierte a los profesores que, al implementar una sola estrategia de enseñanza y evaluación, por ejemplo: estrategias magistrales frente a pruebas escritas, se privilegia un grupo de estilos de aprendizaje y se pone en franca desventaja a los demás. Por esta razón, se hace necesario siem- 
pre la articulación entre diferentes estrategias que conecten el plano teórico con la experiencia práctica, es decir, un Saber Hacer.

Es imprescindible, primero, dedicar el tiempo necesario, acorde a los momentos, para la conceptualización abstracta sea virtual o presencial, antes del inicio de actividades en el laboratorio de simulación, pues cuando no se destina este tiempo en el aula, se observa con frecuencia el fenómeno de un profesor, usando un escenario del laboratorio con simuladores y equipamiento, teniendo que implementar una clase magistral sin simulación, debido a que sus estudiantes no tienen unos conceptos previos del tema que se pretende abordar, este escenario más allá del impacto negativo que tiene en el proceso de aprendizaje del estudiante genera unos sobrecostos administrativos importantes en el ecosistema del laboratorio (ocupar un escenario de experimentación en simulación clínica tiene un costo más elevado que usar un aula o un espacio virtual, figura 4).

Figura 4. Conceptualización abstracta y relación con Miller: aprendizaje de los conceptos. Laboratorio de Simulación Clínica, Universidad Cooperativa de Colombia.

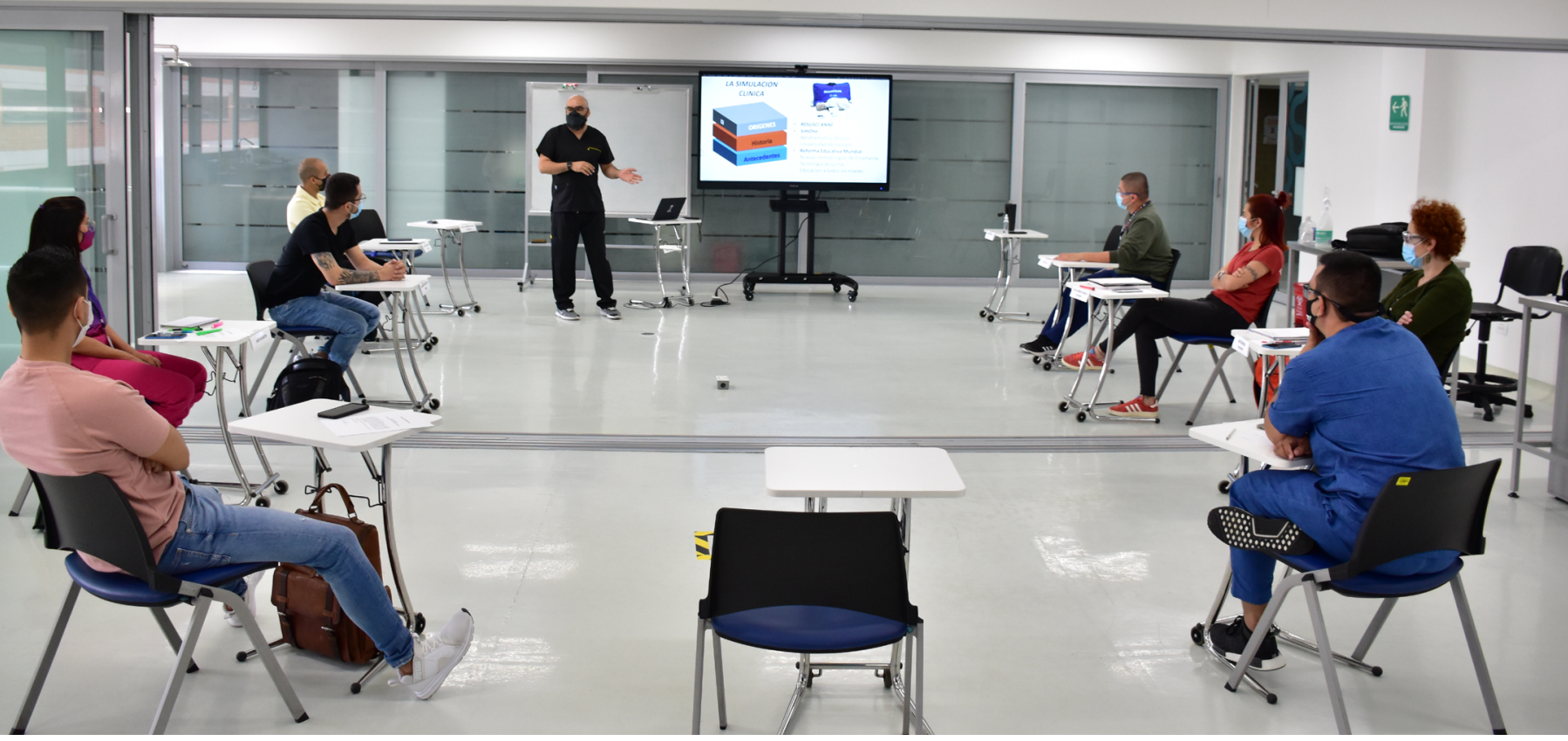

Fuente: archivo personal de Carlos Álvarez (2020). 
Las preguntas para la evaluación del conocimiento no solo hacen parte de las estrategias de evaluación en el aula, como parte de lo definido en el Diccionario de Simulación en Salud [18]. Las pruebas escritas pueden ser usadas dentro del laboratorio en circuitos evaluativos como la Evaluación Clínica con Objetivos Estandarizados (ECOE) que, de manera resumida, se puede describir como una estrategia evaluativa (también hay ECOE formativos) basada en el montaje de estaciones con o sin simulación y para cada una se establece la valoración de un aprendizaje sustentado generalmente en la descripción de un caso clínico, o paciente estandarizado, frente al cual el estudiante debe realizar una acción o conjunto de acciones. En cada estación un docente bajo una lista de chequeo previamente diseñada y consensuada en equipo profesoral va ejecutando la valoración que en ella se solicita, a través de una cámara de Gesell, por ejemplo.

\section{Experimentación concreta (CE)}

Pasar de la conceptualización abstracta a la experimentación concreta permite captar la experiencia, a través de la implementación de escenarios simulados de destrezas (el reto consiste en cómo este tipo de experiencia se puede materializar dentro de un laboratorio de simulación clínica). En estos escenarios se confronta lo teórico con lo práctico y se le debe garantizar al participante la posibilidad de repetir los ejercicios que involucran habilidades psicomotrices. Retomando lo planteado por Ericsson [19], los escenarios simulados deberán procurar mantener una lógica de lo simple a lo complejo para el desarrollo gradual del desempeño de la habilidad (figura 5).

\section{Experimentación concreta y relación con Miller, momento evaluativo}

La experimentación concreta de Kolb ( $\mathrm{CE}$ ) como método de enseñanza, el Sabe Cómo y el Demuestra Cómo de Miller se encuentran en el laboratorio de simulación clínica cuando se requiere evaluar las habilidades psicomotrices 
Como estamos en un momento evaluativo de las habilidades y destrezas, el profesor procurará, con los recursos que disponga en su laboratorio, no intervenir en el proceso evaluativo, sea contestando preguntas inapropiadas para el momento, o gestos de aprobación o negación frente a las acciones del estudiante; es decir, en este punto hablamos de una posición neutral durante el desarrollo de la actividad o la ubicación del profesor alejado de la órbita visual del estudiante durante el escenario evaluativo con simulación.

En la actualidad, hay diversos laboratorios de simulación clínica que han desarrollado ambientes clínicos versátiles donde el profesor puede estar detrás de un vidrio que le permite observar y no ser observado con el objetivo de no interferir, en lo posible, con el ambiente simulado y permita mayor objetividad a la prueba dentro del laboratorio.

En este punto del análisis, cabe preguntarse, en la lógica del círculo del aprendizaje: ¿cuál es la diferencia entre la experimentación concreta (CE) y la experimentación activa (AE)? Hasta aquí, hemos dado parte de la respuesta, pues hemos relacionado $\mathrm{CE}$ directamente con el logro de destrezas duras y necesarias para abordar, posteriormente, un campo experiencial de un contexto más complejo donde las habilidades básicas entrarán a hacer parte y fundamento de otras habilidades mayores que son cruciales para la solución de problemas y que, en el ámbito de Kolb, se denominaría AE.

\section{Experimentación activa (AE)}

Experimentar activamente implica la actividad en escenarios donde los estudiantes tengan una participación protagónica, en que las decisiones sobre sus actos tengan una consecuencia en los resultados de lo experimentado [17]. Lo anterior concuerda con lo que comprendemos por escenarios de alta realidad o "alta fidelidad" [18]. Este tipo de escenarios permite la simulación fidedigna de múltiples factores de la vida real, buscando generar en los participantes 


\section{Experimentación activa y relación con Miller, momento evaluativo}

Miller, en su propuesta de evaluación piramidal, propone el Demuestra Saber (Shows How). Esta demostración de saber puede ser evaluada mediante un escenario de simulación estandarizado como gold estándar en las áreas clínicas, pero de gran aplicabilidad en otras disciplinas no clínicas como el Derecho y las Ingenierías donde también se implementan escenarios de simulación.

Cuando resaltamos, nuevamente, que se debe evaluar con las estrategias que se ha enseñado, ubicamos intertextualidad entre Miller y Kolb, pues si pretendemos generar evaluaciones mediante escenarios realistas estandarizados será porque ya hemos sometido a los participantes a este tipo de escenarios de alta fidelidad en los momentos formativos, los cuales buscan trabajar con errores y aciertos cotidianos en la práctica para, posteriormente, ser analizados o reflexionados con el acompañamiento de todo el equipo participante y del profesor con entrenamiento en debriefing.

Algunos de los errores más comunes que hemos podido observar en la dinámica de los laboratorios de simulación con los profesores con poco entrenamiento en simulación o ninguno son:

- Usar el escenario simulado solo como evaluación y no como estrategia formativa.

- Evaluar sin tener en cuenta los diferentes grados de complejidad de los escenarios implementados en los momentos de aprendizaje.

- Evaluar con un equipo o simulador desconocido por el participante.

- Crear escenarios de simulación sin previa preparación o estandarización por medio de guías de creación de escenarios. 
- No hacer evaluaciones formativas (debriefing) después de los escenarios de simulación que lo ameriten.

En relación con esta última consideración, resaltamos que la evaluación sumativa debe guardar una relación directa con evaluaciones formativas previas. Una evaluación formativa en que el debriefing cumple un papel fundamental como ensayo-error mediado por la reflexión y no por el enjuiciamiento punitivo. Se trata de observar lo ocurrido en el escenario que se ha desplegado para mejorarlo.

Adicionalmente, "cuando se transita de la Experimentación Activa (AE) hacia la Observación Reflexiva se genera la transformación de la experiencia" [17], entonces, nos ubicamos en uno de los momentos más relevantes dentro de los escenarios, donde se busca generar una actitud reflexiva en los participantes que permita la exploración de los puntos de vista de los estudiantes sobre los acontecimientos de lo experimentado en el laboratorio. En su denominación básica, el debriefing está definido como "conducir una sesión luego de un evento de simulación donde los educadores, instructores, facilitadores y los estudiantes reexaminan la experiencia de simulación con el propósito de avanzar hacia la asimilación y adaptación del aprendizaje para futuras situaciones" [18, p9]. El debriefing, después de una actividad simulada, permite aterrizar conceptos, "retroceder la película" y poder entender de una manera más clara el motivo del escenario simulado (figura 7).

Esta visión de debriefing es compatible con la observación reflexiva, momento en que un grupo de participantes con estilos de aprendizaje más analíticos (figura 2) será beneficiado de este acto de reflexión, además de aprender de algunos errores que pudieron cometer en la fase activa del escenario en que los más inclinados a los estilos concretos y activos pudieron expresar algunas ventajas niveladas por los analíticos en el debriefing. 
Figura 7. Observación activa: debriefing. Laboratorio de Simulación Clínica, Universidad Cooperativa de Colombia.

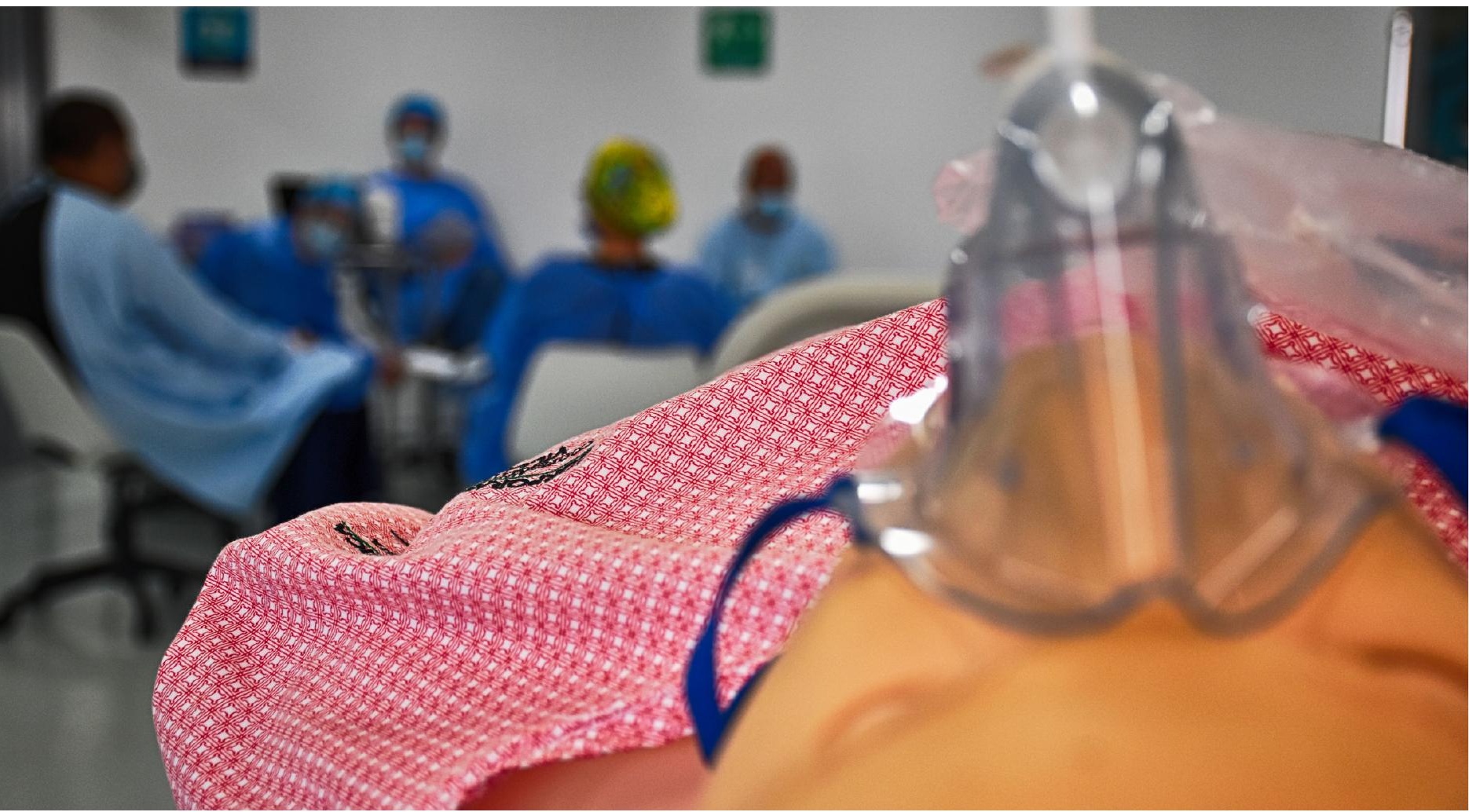

Fuente: archivo personal de Carlos Álvarez (2020).

Son varias las técnicas y los estilos de debriefing, teniendo en común la ubicación del estudiante como protagonista a la hora de ser escuchado para generar en todos los participantes una "práctica reflexiva" [20]. La cúspide de la pirámide de Miller describe el Hacer encadenado (Does) con cada uno de los elementos piramidales anteriores. En este punto, la evaluación de hacer encadenado se ve enriquecido con la introducción de la observación reflexiva de Kolb que, aplicada en el contexto de la simulación, permite la práctica del debriefing la cual, en algunas de sus versiones más estructuradas [20], ofrece una doble intervención. Por un lado, sobre los procesos de pensamiento llamados "marcos mentales" con los que se llega al proceso educativo modelándolo de antemano, por el otro lado, sobre el efecto de estos en los hechos ejecutados 
por los participantes en los ejercicios simulados, llamados acciones. Un debriefing con buen juicio interviene ambos componentes, lo que redunda en resultados distintos: acciones, al lograr una modificación de raíz (proceso de pensamiento), hasta el resultado (del hacer).

La evaluación con simulación: círculo del aprendizaje, competencias y taxonomía soL0

Para abordar los puntos de encuentro en esta triada, se propone la siguiente ruta: abordar para cada uno de ellos los aspectos conceptuales que le tributa al cruce que nos proponemos, y cerrar los puntos de intersección como un todo a la luz de lo que creemos los unifica: la evaluación. Para esto, debemos remitirnos de nuevo a la figura 3. Como se mencionó antes, el círculo del aprendizaje (o la teoría del aprendizaje experiencial) aporta puntos esenciales a nuestra propuesta de acople. A continuación, hilvanamos los aspectos clave del círculo del aprendizaje, que nos sirven para el propósito de vincularlo con el marco de competencias:

- El círculo del aprendizaje señala una ruta acoplada: sus componentes se sirven mutuamente en franca relación de dependencia unos con otros. Un paso a paso que los aprendientes deben recorrer, pues se trata de una dialéctica que abarca desde lo simple a lo complejo.

- Es un círculo que, a modo de circuito, refiere componentes donde cada uno dona al otro los requisitos necesarios para su completo desarrollo.

- Un círculo compuesto por círculos concéntricos que van formando una espiral, dado que el aprendizaje adquirido hoy se nutre constantemente con nuevos componentes teóricos-prácticos y otros desafíos resolutivos; una espiral de aprendizaje a lo largo de la vida cuya garantía está dada por la 
no desconexión entre componentes, sino su interdependencia. El punto de partida, aunque señala el mismo punto de llegada, lo es en tanto circuito mas no se llega del mismo modo de cómo se partió al inicio, sino más robusto: con elementos de la experiencia, de la práctica clínica, sea simulada o en campo, que nutren del mejor modo la experiencia del aprendizaje.

- El aprendizaje es un circuito para la adquisición de conocimientos y destrezas (teórico-práctico) y actitudes (resolución de problemas), según inferimos en la figura 1: su fuerza radica en la experimentación dada por el relacionamiento entre la adquisición de conocimientos-destrezas, la capacidad resolutiva o un saber hacer con lo que se sabe.

- Aprender siempre se da en conjunción con otros con quienes se acuerda, polemiza y consensua; una especie de cognición distribuida (el saber está repartido y fortalecido por la experiencia individual), medida por artefactos (simuladores, por ejemplo), tecnologías (plataformas), técnicas (manuales de aptitudes), discursos (los saberes), normas (como ser con otros según las instituciones), que le sirve al desempeño profesional cuando de trabajar en equipos se trata.

- Esta forma del aprendizaje experiencial está encaminado a fortalecer la práctica clínica propia del desempeño del futuro profesional.

Visto así, concluimos que, desde el punto de vista de las competencias, y tal como las hemos definido antes, podemos conjeturar que se articulan al círculo a modo de dominios de un Saber (teorías disciplinares, es decir, adquisición de conocimientos), Hacer (procedimental, es decir, adquisición de destrezas) que, en conjunción con el Ser, desde el cual se relaciona, explica, analiza o argumenta (resuelve problemas, es decir, actitudinal), conformando una triada 
que avanza en grados de complejidad hacia el logro de la competencia en el marco de enseñanza-aprendizaje.

Sin embargo, ¿qué relación podemos establecer entre el círculo del aprendizaje y la taxonomía solo, en tanto base conceptual y operativa para la evaluación llevada a cabo mediante una rúbrica? El círculo del aprendizaje se ensambla sin esfuerzos a la taxonomía solo de Biggs y Collis [12], acrónimo de Structure of the Observed Learning Outcome, es decir, estructura del resultado observado del aprendizaje.

Como en el caso anterior, tomemos los aspectos conceptuales de cruce. Para ello, comenzaremos por los más generales para situarnos en contexto y luego a aquellos que ya han sido modelados en la UCC, bajo la formulación de un Modelo Educativo Crítico con Enfoque de Competencias.

- En primer lugar, recordemos que, con la taxonomía solo, los autores proponen una clasificación que refiere el nivel cognitivo desarrollado por los aprendientes y que se denota por verbos que refieren grados de complejidad en la escala o taxonomía solo.

- Así, en un nivel cognitivo uniestructural, el aprendiz identifica un aspecto del sistema, no ve la multiplicidad de ellos y menos una mínima relación. Por ello, los verbos para identificar al aprendiente en este nivel cognitivo son algunos como los que propone la figura 3, identificar, por ejemplo. Mientras que, en el nivel relacional, el pensamiento del aprendiente denota la complejidad que precisa relacionar, analizar, explicar o aplicar, y en el nivel mayor, abstracto ampliado, entramos al campo del aprendizaje que no solo relaciona dentro y entre sistema disciplinar donde opera, sino que sale de su propio forro, extiende las alas del análisis, de la aplicación o de la relación 
dentro y entre sistemas hacia el mundo: sale al contexto; por eso, los verbos son teorizar, generalizar, hipotetizar.

- En suma, el nivel pre-estructural, uniestructural y multiestructural se corresponden con operaciones cognitivas superficiales basado en nociones desarticuladas y de tipo cuantitativas (a lo sumo, se enumeran sin una relación de función y contexto), y un relacional y abstracto ampliado para señalar operaciones complejas o cualitativas (figura 8).

- La UCC adoptó en su fundamento esta taxonomía, con los siguientes ajustes y conceptualizaciones, que sirven a nuestro propósito de articulación:

- Adoptar los niveles taxonómicos solo, excepto el nivel pre-estructural.

- Con este ajuste, se propuso esta taxonomía como la columna vertebral para abordar el estado de desarrollo de la competencia.

- La valoración de este estado de desarrollo de la competencia estaría mediada por un instrumento como la rúbrica.

- Se ajusta este instrumento a la taxonomía para cada una de las dimensiones de la competencia, Ser-Saber-Hacer; además, se divide cada nivel solo y se propone un compendio de verbos, con la respectiva acepción tomada de la literatura (Diccionario de María Moliner, entre otros) para cada nivel y en directa relación con las disciplinas que se ofrecen en la institución.

- Con ello, la ucc diseñó una retícula de la rúbrica. A modo de ejemplo, presentamos la siguiente retícula de la rúbrica tomada de la Dirección Nacional de Gestión de Programas de la Universidad Cooperativa de Colombia, que expone la estructura general que hemos mencionado (tabla 1). 


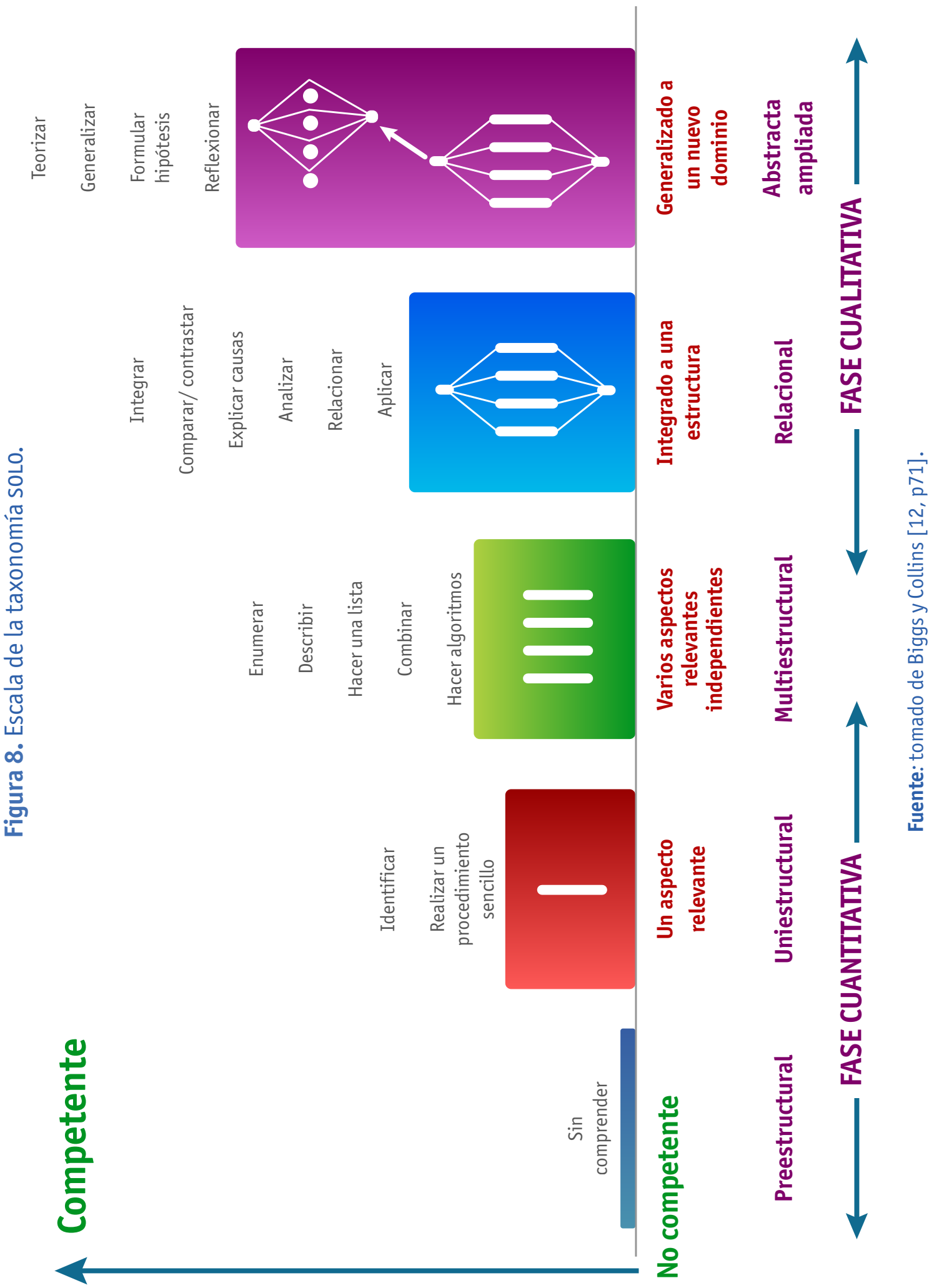


Tabla 1. Retícula rúbrica institucional ucc.

Niveles de la taxonomía SOLo de John Biggs y Collis

\begin{tabular}{|c|c|c|c|c|c|}
\hline $\begin{array}{c}\text { Elemento de } \\
\text { Competencia }\end{array}$ & Escala & Uniestructural & Multiestructural & Relacional & $\begin{array}{c}\text { Abstracto } \\
\text { Ampliado }\end{array}$ \\
\hline \multirow{2}{*}{ Saber } & 1 & Verbo 1 & Verbo 4 & Verbo 7 & Verbo 10 \\
\cline { 2 - 7 } & 3 & Verbo 2 & Verbo 5 & Verbo 8 & Verbo 11 \\
\cline { 2 - 7 } Hacer & 1 & Verbo 3 & Verbo 6 & Verbo 9 & Teorizar \\
\cline { 2 - 7 } & 3 & Verbo 2 & Verbo 5 & Verbo 8 & Verbo 11 \\
\cline { 2 - 7 } & 5 & Verbo 3 & Verbo 6 & Verbo 9 & Innovar \\
\hline \multirow{2}{*}{ Ser } & 1 & Verbo 1 & Verbo 4 & Verbo 7 & Verbo 10 \\
\cline { 2 - 7 } & 3 & Verbo 2 & Verbo 5 & Verbo 8 & Verbo 11 \\
\cline { 2 - 7 } & 5 & Verbo 3 & Verbo 6 & Verbo 9 & Criticar \\
\hline
\end{tabular}

Fuente: tomado de Restrepo [14].

Cada profesor debe complementar esta retícula con los verbos respectivos que señalan grados de la competencia seguidos de un descriptor que lo sitúa, e indicar la operación concreta que el aprendiente debe demostrar en dicho nivel de la taxonomía y en cada dimensión de la competencia, lo que implica que si hay un verbo con una complejidad dada, el descriptor u operación para su materialización deberá preservarla. Este acople de componentes da lugar a un instrumento de medición con cuyos verbos se calibra el estado de desarrollo de la competencia: la rúbrica de la UCC, diseñada, en nuestro caso, para cada programa de curso que, a su vez, ha sido previamente diseñado 
por competencias, ambos columna vertebral del modelo dentro del aula. La rúbrica es un instrumento con la cual el estudiante es evaluado o valorado a lo largo de un periodo académico de tal forma que el estado de desarrollo que se va evidenciando con las diferentes estrategias evaluativas y acciones educativas que ellas delatan va implicando planes de mejora por parte del profesor mediados por el análisis con el estudiante y unos compromisos de superación que sin duda mejoran los resultados del aprendizaje ${ }^{1}$.

En el círculo del aprendizaje, detectamos una bisagra que lo une al marco de las competencias: un Saber llamado conceptualización abstracta, que sitúa, orienta y fundamenta el Hacer, o acciones procedimentales, llamadas experimentación concreta, de tal manera que, bajo la dimensión del Ser, el significado de Analizar, perfectamente equiparable a la observación reflexiva, acompañe la toma de decisiones que todo desempeño profesional exige. Esta es una conexión necesaria para llegar a un nivel relacional 1, como el mínimo necesario y suficiente que delata el logro de la competencia bajo la lupa de un instrumento como la rúbrica, en los estándares de nuestra institución.

Dicho lo anterior, podemos concluir para nuestro desafío de articulación que si hacemos la operación de pensar el círculo del aprendizaje como el fundamento de una evaluación completa de la competencia, en una institución cuyo currículo se sitúa justo en el ámbito de las competencias, la medición de los resultados del aprendizaje deberá tener como instrumento una rúbrica como la explicitada, que marque el logro de la competencia en el Ser-SaberHacer en el nivel relacional 1 como mínimo, asegurado por verbos y descriptores cuya escala dé cuenta de las operaciones cognitivas necesarias para asegurar su logro.

1 Información sobre la taxonomía solo y el Modelo Educativo Crítico con Enfoque de Competencias puede consultarse en la colección Green Papers de Ediciones ucc [5, 12, 13,15]. 
Aspectos normativos: la simulación y el decreto 1330, Resoluciones 015224 y 021795 del Ministerio de Educación Nacional de Colombia

Como se sabe, en el ámbito de la educación superior toda estrategia educativa deberá esforzarse por hacer caso a un contexto, que necesariamente rige su actuar y objetivos; este puede ser interno institucional (proyecto institucional, sistemas de calidad, entre otros) o gubernamental (ministerios o similares). La simulación no es ajena al contexto en el que la educación superior se produce y se autoevalúa. Hoy, el país asiste a la implementación, por parte del Ministerio de Educación Nacional (MEN), del Decreto 1330 [1] que, como norma rectora, se acompaña por dos resoluciones mencionadas en el título de esta aparte y que indican el cómo, para qué, el cuándo de aquella. En todo caso, esta normatividad, en su conjunto, busca garantizar, mediante la regulación de los procesos de registro calificado y la acreditación de alta calidad de las Instituciones de Educación Superior (IES), su quehacer institucional, el cumplimiento de la promesa de valor pactada con el aprendiz. La normativa también llama a repensar el enfoque y la diversidad de escenarios para aprender (ambientes de aprendizaje), en los cuales la simulación ocupa un lugar de protagónico.

A continuación, hacemos un corto análisis (y solo sobre algunos aspectos de la norma para ilustrar su impacto y a que nos conmina en el plano de la simulación, pues cada IEs tendrá detectado otros aspectos que actúan acoplados a la simulación, tales como los ambientes prácticos de aprendizaje, la infraestructura física, tecnológica, la capacitación profesoral, entre otras), articulado entre el Decreto y la simulación como estrategia inscrita en una malla curricular en particular:

a) En primer lugar, consideramos que la simulación, ciertamente, puede ser catalogada como una estrategia dentro en un marco más general, una metodología y que, en ese sentido, deberá estar acompañada por la institu- 
ción de educación superior en la que ella se adopte. Al respecto, el artículo 2.5.3.2.2.6 menciona: "Metodología [...] es un conjunto de estrategias educativas, métodos y técnicas estructuradas y organizadas para posibilitar el aprendizaje de los estudiantes dentro del proceso formativo" [15].

b) Esta normativa es clara en asegurar e introducir el concepto de resultados del aprendizaje como parte de las funciones sustantivas de una institución de educación superior en función de la promesa de valor pactada con el estudiante. El concepto de resultados del aprendizaje se le nombra en varias secciones del decreto como uno de los aspectos claves a contemplar y del cual dar cuenta con resultados evidenciables, que para el caso de la Universidad Cooperativa no es más que el logro de la competencia declarada en cada programa de curso y valorada a través de la rúbrica, tema novedoso en los sistemas de aseguramiento de la calidad, hasta hoy enfocados en la evaluación de capacidades y procesos. Los resultados se definen como "las declaraciones expresas de lo que se espera que un estudiante conozca y demuestre en el momento de completar su programa académico. Que dichas declaraciones deberán ser coherentes con las necesidades de formación integral y con las dinámicas propias de la formación" [15, p4]. Desde esta óptica, la simulación ofrece un potencial que asegura de manera indiscutible parte de este aspecto,

c) Desde el punto de vista del desempeño, el decreto en cuestión estipula que "cada programa que conforma el proceso formativo por ciclos propedéuticos debe conducir a un título que habilite de manera independiente para el desempeño laboral como técnico profesional, tecnólogo o profesional universitario, según lo definido por la Ley 749 de 2002” [15, p20]. Según lo que venimos afirmando a partir del apartado "Aspectos de implementación: la simulación y la evaluación" de este libro, la simulación le apunta a un entrenamiento previo, cognitivo, experiencial, práctico y 
actitudinal del aprendiz de las Ciencias de la Salud, como los que propone la vida real, abonándole al desempeño posterior en la vida profesional.

d) Estableciendo curvas de aprendizaje debidamente establecidas para un curso en que la simulación sea protagónica, y que deberá dar cuenta del tiempo mínimo-promedio a dedicar por parte del estudiante para la adquisición de la destreza que lo declare competente, lo que se traduce en un número de repeticiones, una vez y previamente el profesor o facilitador, bajo el formato que sea necesario, indique lo que se debe lograr y esté consignado en una guía con la cual, en un ambiente simulado, o ambiente práctico de aprendizaje, el aprendiz lo ejercite en sus horas de trabajo independiente, debidamente asentadas como registro para la medición de indicadores de logro o desempeño.

e) En el artículo 2.5.3.2.6.5, el Decreto menciona que las especialidades médico-quirúrgicas "son los programas que permiten al médico la profundización en un área del conocimiento específico de la medicina y la adquisición de los conocimientos, desarrollo de actitudes y destrezas avanzadas para la atención de pacientes en las diferentes etapas de su ciclo vital, con patologías de los diversos sistemas orgánicos que requieren atención especializada" $[1, \mathrm{p} 9]$.

f) Por último, este Decreto declara que "la institución deberá contar con la disponibilidad de los medios educativos para cada modalidad (presencial, a distancia, virtual, dual u otros desarrollos que combinen e integren las anteriores modalidades) estableciendo estrategias que atiendan las barreras acceso y características de la población" [1, p14], esto supone un reto en varios aspectos. La pandemia por COVID-19 supuso cambios en los escenarios de formación y la virtualidad cobró aún más importancia de la que se declaró en el decreto, que se formuló mucho antes de que semejan- 
te contingencia se cerniera sobre el globo, en general, y las instituciones, en particular. Este evento global causó que tuviéramos que reaccionar rápidamente, de modo que se pudiera planificar la continuación de estas prácticas, teniendo en cuenta el confinamiento, que ha probado que mucho de lo que hacía presencialmente puede seguirse desarrollándose en este tipo de escenarios virtuales. Esto exige varias cosas: 1) repensar, mas no decretar, cuáles son las prácticas mínimas necesarias, suficientes e ineludibles que se deben desarrollar; 2) considerar cómo la simulación en estas prácticas presenciales evita acercamientos con pacientes reales, $y$ 3) diversificar los escenarios simulados y apostarles a aquellos que se desarrollan en la virtualidad lo que demanda innovación no solo del medio, sino de la forma en que este se posiciona en el currículo, delimitando su alcance acorde a la modalidad que le sirva. 


\section{LA SIMULACIÓN COMO} ESTRATEGIA PLANIFICADA 
T a simulación y sus equipos han logrado grandes desarrollos, se usa de manera rutinaria en las Universidades del país y en la región. Para llevar a cabo una práctica planificada de simulación, el profesor deberá tener en cuenta los siguientes pasos antes de citar a los participantes en el laboratorio de simulación:

1. Verificar la inserción de la simulación en el plan curricular del programa, conociendo no solo su plan de actividades prácticas, sino también las de los semestres y cursos que se articulan con el suyo, de tal manera que la simulación guarde coherencia y pertinencia a lo largo del plan de estudios. Esto exige que, desde las direcciones de los programas, se invite a los profesores a cargo de cursos que implican la simulación, a llegar a unos acuerdos que permitan una clara articulación entre los cursos comprometidos. Para las actividades de simulación que acompañan los cursos de extensión académica o venta de servicios, se recomienda revisar el plan de formación enfocado a determinar las habilidades y destrezas, recursos requeridos y el ambiente donde la actividad será ejecutada.

2. El profesor determinará, en su programa de curso, en qué momento de su desarrollo debe planificar su(s) práctica(s) específica(s), de tal manera que esta contribuya al logro de la competencia, sea en la formación o como recurso para la evaluación (una vez haya dominio de habilidades y destrezas).

3. La guía de práctica de laboratorio es una herramienta que posibilita un orden de desarrollo coherente y sistemático de la práctica con simulación. Dentro de la UCC, se utilizan dos tipos de guía: 
a. Guía de creación de escenarios de simulación: en que el profesor ingresa todas las características logísticas y temporo-espaciales para la ejecución de su actividad dentro del laboratorio de simulación. Esta guía genera una conversación entre el profesor y el personal del laboratorio. Este documento hace parte de la gestión interna de la ejecución de la práctica, por lo tanto, no es de interés del estudiante. Recomendamos que el profesor preste especial interés en el tipo de simuladores y recursos que solicita para que sean coherentes con las habilidades y destrezas a desarrollar.

b. Guía de escenario de simulación para el estudiante: en el marco de las competencias propias del curso, describe un paso a paso de cómo debe ser ejecutado el procedimiento, de tal manera que tenga la posibilidad de reproducirlo cuantas veces sea necesario, incluso estando solo en el laboratorio en la denominada práctica libre, hasta lograr la habilidad o destreza descrita en la guía. Esta guía genera una conversación entre el profesor y el estudiante. Cabe recordar que el estudiante puede repetir el procedimiento, pero siempre estará antecedido por una demostración del profesor del Cómo se hace.

4. Desarrollo de la práctica.

5. Después de la ejecución de la práctica, retome las observaciones de los participantes, las del equipo del laboratorio y las suyas propias como profesor, para ajustar los puntos problemáticos de la guía y desarrollar un escenario cada vez mejor.

6. Para las prácticas de la modalidad combinada, híbrida o presencial, existen herramientas y tecnologías, que permiten la simulación virtual. Por ejemplo, la tecnología cisco Webex facilita la realización de prácticas demostrativas por parte del profesor, que podrían ser grabadas y enviadas 
a modo de preparación del estudiante antes de la práctica presencial en el laboratorio de simulación. Por otro lado, se encuentran también los softwares de Simulación Virtual, que permiten trabajar competencias en los estudiantes, enfocadas en el Saber y el Ser, en la medida en que mejora la toma de decisiones.

Durante la pandemia por Covid-19, y ante la necesidad de implementar o incrementar las actividades de simulación virtuales, se han venido impulsando novedosas estrategias de simulación, que combinan recursos audiovisuales de alta fidelidad dentro del laboratorio de simulación con su respectivo equipo humano, conectados mediante plataformas tecnológicas de comunicación virtual, como zoom o Microsoft Teams, y mediado por un evento sincrónico programado en que se conectan los participantes desde casa con las personas que se encuentran en vivo en el laboratorio. Los participantes del evento virtual se encargarán de generar las órdenes en relación con la toma de decisiones alrededor del caso por resolver. Esta estrategia ha sido denominada "Simulación de alta fidelidad sincrónica". 


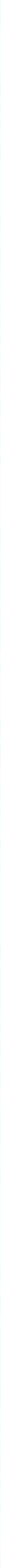


$\mathrm{L}$ as comunidades virtuales de aprendizaje y de práctica se constituyen en una poderosa estrategia a la hora de construir conocimiento colectivo, compartir lo que se sabe, afinar las buenas prácticas, problematizar el saber. Dado que el ejercicio práctico de los saberes supone ajustes de acuerdo con los colectivos humanos en que se ponen en marcha, las comunidades virtuales son un medio potente para que la cognición que hay en cada uno, con los medios adecuados, plataformas para la interacción, unos propósitos claros de para qué vamos a interactuar, y que todo esté inscrito en unos propósitos curriculares declarados, robustecen el proceso académico, sacándolo de las esferas individuales de la interpretación, contribuyendo así a una gestión académica de interés: la creación de una comunidad académica que trabaja en red.

Rizoma es una Comunidad Académica Integrada para el Aprendizaje en Red, un programa que se desarrolla en la Ucc con el propósito de contribuir con la apropiación y materialización del modelo educativo crítico con enfoque de competencias, a través de comunidades virtuales de aprendizaje y práctica diseñadas en la plataforma Yammer de Office 365. Esta estrategia está centrada en el profesor como agente de cambio que, interactuando de manera multicampus en las diferentes comunidades existentes, debaten y consensuan el programa de curso a impartir en el periodo académico siguiente, comparten recursos académicos para el aprendizaje, entre otros, todo ello como aporte al trabajo colaborativo y en red. Estas comunidades dan respuesta a las demandas del Acuerdo 02 del Consejo Nacional de Educación Superior (CESU), promulgado en el 2020, normativa que, en su Factor 10, conmina a las Instituciones de Educación Superior a que promuevan "la consolidación de 
una comunidad de profesores caracterizada por su diversidad, compromiso y participación para el logro de la misión institucional” [27]. Justo allí, la estrategia Rizoma da respuesta a esta demanda con comunidades multicampus, aspecto central que se destaca en nuestra misión institucional.

Una de estas comunidades virtuales Rizoma ha estado enfocada en aspectos de evaluación por competencias. Precisamente, en los meses de junio y julio del 2020, impulsamos y desarrollamos una comunidad de profesores con el objetivo de discutir, problematizar e incorporar estrategias de evaluación por competencias que permitan valorar, mediante la rúbrica institucional, el estado de desarrollo de la competencia acorde a cada programa o plan de curso. Sin embargo, esto no es nuevo en este ámbito de la evaluación por Competencias. En el periodo 2018-2019, apoyamos con comunidades de aprendizaje el desarrollo y apropiación de metodologías de evaluación por competencias en el área de salud en el marco de una propuesta mayor (desarrollada por las decanaturas nacionales de Salud: Medicina, Enfermería, Odontología de la UCC), a saber, el diplomado "Estrategias para la Evaluación de Competencias en Salud", llevado a cabo bajo la conducción de expertos temáticos. Para el caso, desde Rizoma se apoyó la iniciativa con el diseño de tres comunidades virtuales bajo un mismo objetivo: discutir y apropiar las estrategias de evaluación por competencias, objeto del diplomado, tales como evaluación 360 grados, ECOE (evaluación clínica, objetiva, estructurada), entre otras. El diseño de las comunidades se realizó en la plataforma Yammer de Office 365, que es desde donde las operamos institucionalmente. Para captar una métrica básica de la interacción, se estableció una figura de líder académico que fuera eje central de las problematizaciones a que ello diera lugar; adicionalmente, un líder de la modalidad virtual, de tal manera que los integrantes tuviesen soporte a este nivel. Como se menciona, estas comunidades actuaron como 
soporte para la apropiación conceptual del diplomado y desde allí contaron, además, no solo con el diseño, la capacitación en comunidad y su funcionamiento, sino el soporte del community manager de nuestras comunidades virtuales que garantizara el "pivoteo" y mantenimiento de la interacción. La interacción de tipo multicampus entre sus agentes (integrantes-profesores y líderes académicos de las tres comunidades procedían de diferentes campus, a saber: Medellín, Villavicencio, Bucaramanga, Pasto, Santa Marta y Bogotá) es el epicentro que delata la existencia misma de la comunidad, interacción que se mide en términos de los archivos compartidos, que denotan horizontes de sentido frente a la evaluación o regímenes de verdad que lo guían, el número de interacciones llevadas a cabo, los likes recibidos en cada posteo hecho por los integrantes, y las temáticas de las interacciones. Una métrica de red que denota las preocupaciones académicas, los consensos, tendencias conceptuales, entre otras. En la tabla 2 se presentan algunos de sus resultados.

Lo anterior es importante para ilustrar la potencia que, como tal, adquieren este tipo de comunidades cuando de la simulación, como articulador de la evaluación, se trata; incluso para la simulación misma como eje problematizador de la pedagogía: poder interactuar en tiempo real con pares académicos que se constituyen en aportantes conceptuales a los que se reconoce como tales (alteridad); poder unificar un horizonte de sentidos: que estemos hablando de lo mismo cuando a ello nos referimos, depurando el campo interpretativo; poder compartir literatura que consideramos de valor frente al tema de interés y debatirla con argumentos, consensuar; compartir experiencias de implementación como buenas prácticas, que minimizan los errores $y$, por lo tanto, aceleran positivamente el logro de los objetivos que se proponen. Todo esto es lo que posibilita una comunidad virtual de aprendizajes y de prácticas académicas. 
Tabla 2. Datos globales de las Comunidades Rizoma de Aprendizaje en el diplomado "Evaluación por Competencias en Salud", Decanaturas Nacionales de Salud, Universidad Cooperativa de Colombia, 2018-2019.

\begin{tabular}{|c|c|c|c|c|}
$\begin{array}{c}\text { Número de } \\
\text { comunidades } \\
\text { virtuales }\end{array}$ & $\begin{array}{c}\text { Número } \\
\text { total de } \\
\text { participantes }\end{array}$ & $\begin{array}{c}\text { Número } \\
\text { total de } \\
\text { interacciones }\end{array}$ & $\begin{array}{c}\text { Número total } \\
\text { de archivos } \\
\text { compartidos }\end{array}$ & $\begin{array}{c}\text { Temática de las } \\
\text { interacciones }\end{array}$ \\
\hline 3 & 109 & 2388 & 117 & $\begin{array}{c}\text { Modelo Educativo, } \\
\text { Evaluación por } \\
\text { competencias, } \\
\text { Evaluación ECOE, } \\
\text { Evaluación formativa } \\
\text { yvaluación 360 } \\
\text { grados. }\end{array}$ \\
\hline
\end{tabular}

Fuente: adaptado de Espinal Correa [16]. 


1 modelo educativo de la ucc, desde su inicio, en la interacción e integración de las Ciencias Básicas y las Ciencias Clínicas con su circuito de aprendizaje en los laboratorios multifuncionales del Ambiente Práctico de Aprendizaje (APA), ha utilizado la simulación clínica en salud como una estrategia de formación y evaluación de competencias genéricas, transversales y específicas del currículo de los programas académicos de salud. La simulación es una herramienta docente disruptiva que le apuesta a cambiar el statu quo tradicional en que el protagonista es el profesor y los participantes cumplen un papel pasivo (receptores de la información), el aprendizaje es unidireccional, el estudiante escucha y aprende lo mejor para él, según el enfoque del profesor.

Es importante agregar que la simulación no es una forma de aprender con "maniquís". Los insumos y dispositivos son los medios para lograr la adquisición de habilidades y competencias, así como el nivel de fidelidad depende de la capacidad del instructor, más que del alto desarrollo tecnológico de los simuladores. Una de las grandes ventajas reconocidas de la simulación clínica es que permite recrear el caso real en un ambiente planificado seguro, a través de una estrategia centrada y manejada por los estudiantes, en que el profesor cumple un rol de facilitador y potenciador, permitiéndoles de manera reflexiva analizar sus conocimientos, habilidades técnicas y no técnicas [21], que incluye la comunicación asertiva y el trabajo en equipo [22] en la punta de la pirámide de Miller [23], logrando identificar sus fortalezas, los puntos a mejorar y elaborar un plan de mejora continua colaborativa para evitar hacer daño en los pacientes, que es un principio básico.

Las competencias centradas en el participante le permiten enfrentarse, de manera más segura, al entrenamiento clínico con mejores herramientas, 
desenlaces y satisfacción en el paciente y su núcleo cercano. El desarrollo y la experiencia del laboratorio de simulación, desde el 2011, le permitió a nuestra Universidad, durante la pandemia declarada en el 2020, apoyar la formación y la posterior evaluación de las competencias retadoras generadas por la covid-19, acelerando el desarrollo de las actividades virtuales y mixtas con componentes presenciales, contenidos y elaboración de escenarios virtuales de acuerdo con las necesidades de los estudiantes y los participantes a nivel de los diferentes programas en las áreas de la salud, a la luz de la necesidad de mantener las medidas básicas del autocuidado. La virtualidad llegó para quedarse y en la UCC nos adaptamos a las nuevas necesidades para lograr una mejor salud en las personas.

En nuestro medio, a diferencia de los países de altos ingresos, en que los participantes en las actividades de simulación cumplen unos prerrequisitos, conocimientos y habilidades previas al desarrollo de la actividad formativa o evaluativa, el hallazgo común de nuestros escenarios de simulación clínica de alta fidelidad es que debemos dedicar tiempo importante durante el taller a la adquisición de esos conceptos teóricos y al componente de destrezas técnicas. El proceso formativo en nuestros países debe realizarse de forma secuencial, con talleres enfocados en la base de la pirámide del aprendizaje, conocimientos y habilidades, con mayores retos para alcanzar la punta con el logro del trabajo en equipo.

La evolución del modelo educativo ha permitido promover y fortalecer las características propias de las personas, además del saber, concepto central en la educación tradicional; la formación actual incluye el Saber hacer (habilidades) y el Ser (habilidades no técnicas) con el desarrollo integral basado en el ciclo del aprendizaje de Kolb desde las instituciones educativas. 
La propuesta para implementar la evaluación por competencias con la simulación como ambiente de aprendizaje se fundamenta en la interacción entre la pirámide de Miller y la rúbrica elaborada con la propuesta de la taxonomía solo como la piedra angular para enfocar el estado del desarrollo de la competencia a nivel del Ser, el Saber y el Hacer.

En lo relacionado con la normatividad del Ministerio de Educación por el Decreto 1330 en Colombia, la simulación cumple los propósitos de calidad expresados en dicho documento, justifica utilizar la pirámide para la evaluación y medición de impacto en los involucrados, tanto para el talento en formación como para la atención de las personas; nuestro objetivo principal es prestar servicios asistenciales para mantener o mejorar las condiciones de vida de las personas. Vasco le agrega un componente a la pirámide de Miller en la punta [24]: los desenlaces o resultados en el aprendizaje y en las condiciones de salud para todas las personas; su propuesta se fundamenta en que los conocimientos y las habilidades técnicas y no técnicas, del Ser en el Saber y el Hacer, buscan una atención en salud con calidad y seguridad para lograr mejores resultados en los pacientes [25].

Nuestro papel como facilitadores en la formación y evaluación del proceso educativo del talento humano en salud es un reto, debemos lograr estimular a los participantes para explorar las habilidades y competencias a través del Saber y el Hacer del Ser. La simulación permite explorar los modelos mentales de las personas para lograr que, utilizando la práctica reflexiva, desarrolle su plan de mejora continua con la consecuencia favorable de lograr mejores desenlaces en la asistencia clínica [26]. Es nuestra obligación motivar al personal docente para que evite las clases magistrales dentro del laboratorio multifuncional. Nuestro rol es transversal a todos los actores involucrados en la educación en las áreas de la salud. Nuestra propuesta del modelo educativo es 
integral y la piedra angular para lograrlo en nuestra Universidad Cooperativa es la simulación clínica centrada en el participante, con el fin de que los futuros profesionales adquieran las habilidades y competencias necesarias para lograr ofrecer una mejor atención a las personas de manera que le permitan retornar a las actividades de la vida diaria en iguales o mejores condiciones. Nuestro objetivo es dar mejores herramientas para que las actividades de simulación en la UCC sean más útiles y efectivas, con el cumplimiento de las exigencias gubernamentales y con una propuesta de valor institucional. 



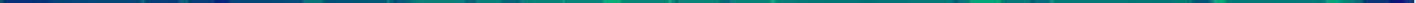


[1] Ministerio de Educación Nacional. (Men). Decreto 1330 de 25 de julio del 2019. Disponible en https://bit.ly/38U1jub

[2] Cooper JB, Taqueti VR. A Brief History of the Development of Mannequin Simulators for Clinical Education and Training. Quality \& Safety in Health Care. 2004; 13(Suppl 1):11-18. Disponible en: https://bit.ly/2VsthtW

[3] Dieckmann DP. La simulación es más que tecnología: el ambiente de la simulación. Instructores en simulación [Internet]; 2018. Disponible en: https:// bit.ly/3jWKG7q

[4] Amaya A. Simulación clínica, un reto curricular de las facultades de medicina, un criterio de calidad de la formación médica [Internet]. Disponible en: https://bit.ly/3trxI40

[5] Unigarro MA. Un modelo educativo con enfoque de competencias. Universidad Cooperativa de Colombia [Internet]; 2017. Disponible en: https://bit. ly/3yZP5ei

[6] Zabalza MA. La enseñanza universitaria: el escenario y sus protagonistas. España: Ediciones Narcea; 2006.

[7] Maestre JM. La formación de expertos clínicos: la práctica reflexiva. Revista Clínica Española. 2014; 4(214):216-220.

[8] Matiz Camacho H. La práctica de la simulación clínica en las ciencias de la salud. Una moda o un imperativo ético. Revista colombiana de cardiología. 2011;18(6):298-300.

[9] Ziv A., Wolpe PR, Small S., et al. Simulation Bases Medical Evaluation: An Ethical Imperative. Academic Medicine. 2003; 78:783-788. 
[10] Gorman PJ., Meier AH, Rawn C, Krummel TM. The Future of Medical Education is no Longer Blood and Guts, it is Bits and Bytes. American Journal Surgery. 2000; 180(5):353-356. D0I: 10.1016/s0002-9610(00)00514-6

[11] Miller G. The Assessment of Clinical Skills, Competence, Performance. Medical Academy. 1990; 65(9 Suppl):63-67. DOI: 10.1097/00001888199009000-00045

[12] Biggs JB, Collis KF. Evaluating the Quality of Learning: The soLo Taxonomy. Londres: Academic Press; 1982.

[13] Biggs JB. Taxonomía solo de John Biggs. Educación y sociedad [Internet]. 2017; 284. Disponible en: https://bit.ly/3tvp31t

[14] Restrepo CJ. Niveles de la taxonomía solo de John Biggs \& Collis. Medellín: Universidad Cooperativa de Colombia, Dirección Nacional de Gestión de Programas, Observatorio para la Gestión de Conocimiento; 2020.

[15] Espinal Correa CE, Moreno ME. Rúbrica parcial para un Programa de curso de Biología Molecular. Universidad Cooperativa de Colombia; 2020.

[16] Espinal Correa CE. Datos comunidades Rizoma. Líder Nacional Proyecto Rizoma. Universidad Cooperativa de Colombia; 2019.

[17] Kolb DA, Kolb AY. The Kolb Learning Style Inventory Guide to Theory Psychometrics, Research \& Applications. Experience Based Learning Systems, Inc. 2013.

[18] Lioce L. Healthcare Simulation Dictionary. Rockville, Agency for Healthcare Research and Quality; 2016.

[19] Ericsson A. Acquisition and Maintenance of Medical Expertise: A Perspective from the Expert- Performance Approach with Deliberate, Practice. Academic Medicine. 2015;90(11):1473.

[20] Rudolph JW, Simon R, Dufresne RL, Raemer DB. There's No Such Thing as “Nonjudgmental" Debriefing: A Theory and Method for Debriefing with Good Judgment. Simulation in Healthcare. 2006;1(1):50. 
[21] Flin R, Patey R, Glavin R, Maran N. Anaesthetists' Non-Technical Skills. Br J Anaesth. 2010;105(1):38-44.

[22] Eddy K, Jordan Z, Stephenson M. Health Professionals' Experience of Teamwork Education in Acute Hospital Settings: A Systematic Review of Qualitative Literature. JBI Database System Rev Implement Rep. 2016;14:96-137.

[23] Williams BW, Byrne PD, Welindt D, Williams MV. Miller's Pyramid and Core Competency Assessment: A Study in Relationship Construct Validity. J Contin Educ Health Prof. 2016;36(4):295-99.

[24] Vasco Ramírez M. Training Future Anesthesiologists in Obstetric Care. Curr Opin Anaesthesiol. 2017;30(3):313-18.

[25] Steadman RH, Burden AR, Huang YM, et al. Practice Improvements Based on Participation in Simulation for the Maintenance of Certification in Anesthesiology Program. Anesthesiology. 2015;122:1154-69.

[26] Larsson J. Monitoring the Anaesthetist in the Operating Theatre - Professional Competence and Patient Safety. Anaesthesia. 2017; 72(Suppl 1):76-83.

[27] Consejo Nacional de Acreditación. Acuerdo 02 de 2020. Disponible en: https://bit.ly/2Y9ZyaB 
En este libro se presenta la simulación clínica como una tecnología que se pone en un lugar privilegiado dentro de la compleja relación de enseñanza-aprendizaje. Acompañada de recursos como los simuladores y estrechamente ligada al campo de la pedagogía y la didáctica, se convierte en una estrategia que contribuye al desarrollo y al potenciamiento de las habilidades y destrezas requeridas por las disciplinas en las que se encuentra inmersa, a la vez que favorece la toma de decisiones del futuro profesional, en nuestro caso, del área de la salud. 